\title{
Nanoparticles: Promising Tools for the Treatment and Prevention of Myocardial Infarction
}

\author{
Qi Pan (D) \\ Jing $X u^{\prime}$ \\ Cen-Jin Wen ${ }^{2}$ \\ Yu-Yan Xiong' \\ Zhao-Ting Gong' \\ Yue-Jin Yang'
}

'State Key Laboratory of Cardiovascular Disease, Department of Cardiology, Fuwai Hospital, National Center for Cardiovascular Diseases, Chinese Academy of Medical Sciences and Peking Union Medical College, Beijing, People's Republic of China; ${ }^{2}$ Department of Cardiology, Peking Union Medical College Hospital, Chinese Academy of Medical Sciences and Peking Union Medical College, Beijing, People's Republic of China
Correspondence: Yue-Jin Yang State Key Laboratory of Cardiovascular Disease, Department of Cardiology, Fuwai Hospital, National Center for Cardiovascular Diseases, Chinese Academy of Medical Sciences and Peking Union Medical College, Beijing, People's Republic of China

Email yangyjfw@126.com

\begin{abstract}
Despite several recent advances, current therapy and prevention strategies for myocardial infarction are far from satisfactory, owing to limitations in their applicability and treatment effects. Nanoparticles (NPs) enable the targeted and stable delivery of therapeutic compounds, enhance tissue engineering processes, and regulate the behaviour of transplants such as stem cells. Thus, NPs may be more effective than other mechanisms, and may minimize potential adverse effects. This review provides evidence for the view that functionoriented systems are more practical than traditional material-based systems; it also summarizes the latest advances in NP-based strategies for the treatment and prevention of myocardial infarction.
\end{abstract}

Keywords: nanoparticles, myocardial infarction, treatment, prevention

\section{Introduction}

The growing burden of ischemic heart disease (IHD) is a major public health issue. The most harmful type of IHD is acute myocardial infarction (MI), which leads to loss of tissue and impaired cardiac performance, accounting for two in five deaths in China. ${ }^{1}$ Timely revascularization after MI, including percutaneous coronary intervention, thrombolytic treatment and bypass surgery, is key to improving cardiac function and preventing post-infarction pathophysiological remodeling. ${ }^{2}$ However, these effective but invasive approaches cannot be used in all patients owing to their applicability, which is limited based on specific clinical characteristics, and the possibility of severe complications such as bleeding and reperfusion injury. ${ }^{2,3}$ Attempts to limit infarct size and improve prognosis using pharmacotherapy (including antiplatelet and antiarrhythmic drugs and angiotensin-converting enzyme inhibitors) without reperfusion has been proven generally inefficient, due to non-targeted drug distribution and side effects, and short half-life of some drugs. ${ }^{1,3,4}$ Consequently, many patients in which this approach is used still progress to cardiac hypertrophy and heart failure. ${ }^{1}$ Growth and rupture of atherosclerotic plaques and the ensuing thrombosis are the major causes of acute MI. ${ }^{4}$ Currently available interventions for atherosclerosis (AS) including statins can reduce acute MI, but the effects vary between individuals, and leave significant residual risks. $^{5-8}$ Some chemotherapies, such as docetaxel ${ }^{9}$ and methotrexate, ${ }^{10,11}$ also seem to have beneficial effects in AS; however, systemic administration of these drugs is limited because of their adverse effects. ${ }^{12}$ The demand for safer and more efficient therapies and prevention strategies for MI is therefore increasing.

Several optimized strategies have so far been explored, one of which is the application of nanoparticles (NPs). These nanoscale particles have been widely 
used in the treatment of tumors and neural diseases. ${ }^{13,14}$ NPs enable delivery of therapeutic compounds to target sites with high spatial and temporal resolution, enhancement of tissue engineering processes and regulation of the behaviour of transplants such as stem cells. The application of NPs improves the therapeutic effects and minimizes the adverse effects of traditional or novel therapies, increasing the likelihood that they can be successfully translated to clinical settings. ${ }^{15-18}$ However, research on NPs in this field is still in its infancy. ${ }^{5,19-21}$ This review summarizes the latest NP-based strategies for managing acute MI, mostly published within the past 7 years, with a particular focus on effects and mechanisms rather than particle types, which have been extensively covered in other reviews (Figure 1). In addition, we offer an initial viewpoint on the value of function-based systems over those based on materials, and discuss future prospects in this field.

\section{The Types and Properties of Nanoparticles}

\section{The Types of Nanoparticles}

A multitude of NP types are currently under investigation, including lipid-based NPs, polymeric NPs, micelles, inorganic NPs, and exosomes. Virus can also be considered as NPs; however they will not be discussed in this review. ${ }^{22}$

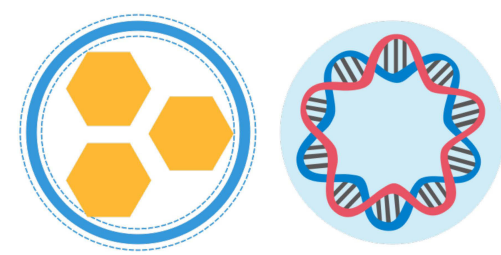

Advanced Drug Delivery Systems

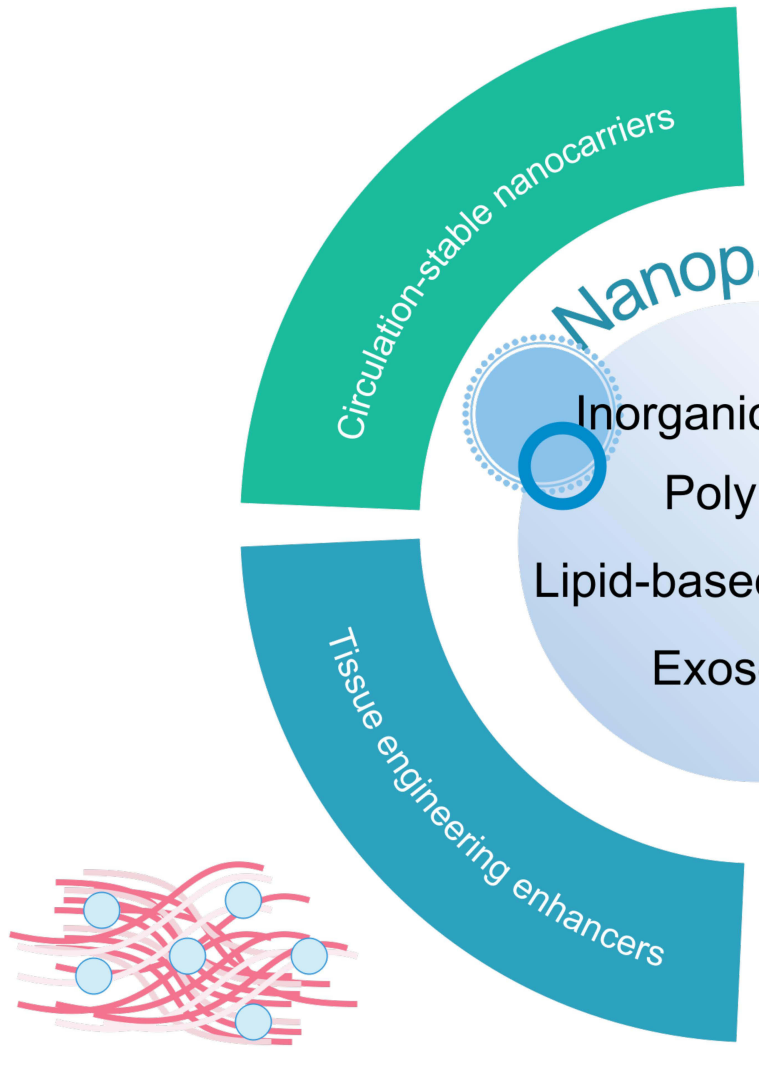

Tissue Engineering Materials

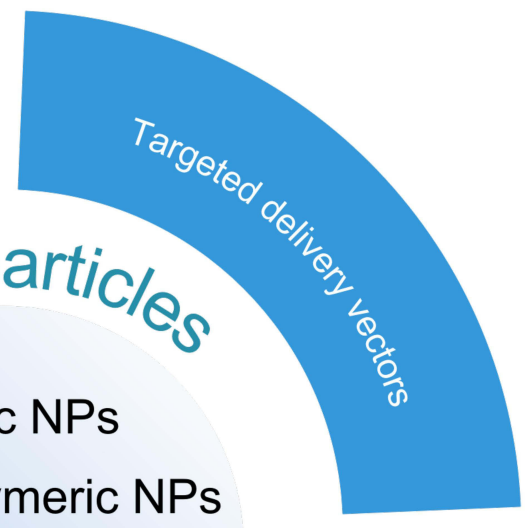

Figure I Overview of nanoparticle-based strategies for the treatment and prevention of myocardial infarction. Nanoparticles are capable of delivering therapeutic agents and nucleic acids in a stable and targeted manner, improving the properties of tissue engineering scaffolds, labeling transplanted cells and regulating cell behaviors, thus promoting the cardioprotective effects of traditional or novel therapies. 
NPs made from different materials show similar in vivo metabolic kinetic characteristics and protective effects on infarcted heart. ${ }^{19,20}$ Function-based NP types, oriented towards a specific purpose, may be preferable compared with traditional types, on account of their practicality in basic research and clinical translation. In this review, we discuss NPs used in the treatment and prevention of MI that fall into the following four categories: 1) circulationstable nanocarriers (polymeric, lipid or inorganic particles); 2) targeted delivery vectors (magnetic or particles modified to improve target specificity); 3) enhancers of tissue engineering; and 4) regulators of cell behavior (Figure 1). We propose that the choice of each NP for any given application should be primarily based on the roles or mechanisms they perform.

Many NPs, whether composed of either naturally occurring or synthetic materials, act as nanocarriers to improve the circulating stability of therapeutic agents. $^{15,16}$ Polymeric NPs comprise one of the most widely employed types, with excellent biocompatibility, tunable mechanical properties, and the ability be easily modified with therapeutic agents using a broad range of chemical techniques. $^{23,24}$ The most commonly used polymer for these NPs is polylactide-co-glycolide (PLGA), which has Food and Drug Administration approval. ${ }^{25,26}$ Recently, there has been a therapeutic emphasis on polydopamine (PDA), from which several related nanomaterials have been created, including PDA NPs and PDA NPknotted hydrogels. ${ }^{27,28}$ NPs made from polylactic acid (PLA), ${ }^{29,30}$ poly-e-caprolactone (PCL), ${ }^{31}$ polyoxalates, ${ }^{32}$ polyacrylonitrile, ${ }^{33}$ chitosan $^{29,34}$ and hollow mesoporous organosilica $^{35}$ have also been constructed and administered in vitro in cells and in vivo in animal models.

Lipid NPs or liposomes are also considered promising candidates for the delivery of therapeutic agents, due to their morphology, which is similar to that of cellular membranes and ability to carry both lipophilic and hydrophilic drugs. These non-toxic, non-immunogenic and biodegradable amphipathic nanocarriers can be designed to reduce capture by reticuloendothelial cells, increase circulation time, and achieve satisfactory targeting. ${ }^{36,37}$ Solid lipid NPs (SLNs) combine the advantages of polymeric NPs, fat emulsions, and liposomes, remaining in a solid state at room temperature. Active key components of SLNs are mainly physiological lipids, dispersed in aqueous solution containing a stabilizer (surfactant). ${ }^{38}$ Micelles are made by colloidal aggregation in a solution through self-assembly of amphiphilic polymers, or a simple lipidic layer of transfer vehicles; ${ }^{39}$ these have been used in cellular and molecular imaging ${ }^{40}$ and treatment $^{41}$ for a long time.

Inorganic NPs used in basic IHD research are classified as metal, metal compounds, carbon, ${ }^{42}$ or silicon NPs, ${ }^{43}$ these are relatively inert, stable, and biocompatible. Gold (Au), ${ }^{44}$ silver $(\mathrm{Ag})^{45}$ and copper $(\mathrm{Cu})^{46}$ are commonly used materials in their production. These NPs can be delivered orally, ${ }^{47}$ or injected intravenously ${ }^{48}$ or intraperitoneally. ${ }^{56}$ However, they are more widely used to construct electrically conductive myocardial scaffolds in tissue engineering. ${ }^{49,50}$ Myocardial patches and scaffolds are promising therapeutic approaches to repairing heart tissue after IHD; incorporating conductive NPs can further improve functionality, introducing beneficial physical properties and electroconductivity. Some organic particles, such as liposomes anchored with poly(N-isopropylacrylamide)-based copolymer groups, are also suitable for the production of effective nanogels or patches for this purpose. $^{37}$

Several metal compounds have been used for treatment of IHD. ${ }^{51-54}$ The application of magnetic particles made from iron oxide has been of particular interest in recent research. These NPs are more prone to manipulation with an external magnetic field, and thus serve as powerful tools for targeted delivery of therapeutics. In addition, modification with targeted peptides or antibodies is another approach to the construction of targeted delivery systems.

Another strategy to protect cardiac performance after $\mathrm{MI}$ is the transplantation of cells; however, the beneficial effects of this are currently limited. ${ }^{58}$ Many NPs can improve the behavior of cells; in this context, they may stimulate cardioprotective potential. In particular, exosomes - a major subgroup of extracellular vesicles (EVs) with a diameter of $30-150 \mathrm{~nm}$, which are secreted via exocytosis $^{55}$ - represent novel, heterogeneous, biological NPs with an endogenous origin. They are able to carry a variety of proteins, lipids, nucleic acids, and other bioactive substances. ${ }^{55-57}$ Mechanistic studies have confirmed that exosomes offer a cell-free strategy to rescue ischemic cardiomyocytes (CMs). ${ }^{59,60}$

\section{The Physical Properties and Modifications of Nanoparticles}

The physical properties of NPs, including size, shape, and surface charge, impact on how biological processes behave, and consequently, responses in the body. ${ }^{61}$ The recommended definition of NPs in pharmaceutical technology 
and biomedicine includes a limitation that more than 50\% of particles should be in a size distribution range of 10-100 $\mathrm{nm} .{ }^{39}$ However, this is not strictly distinguished in studies, so for the purposes of this review, we have relaxed this definition. Small NPs have a faster uptake and processing speed and longer blood circulation half-lives than larger ones; a decreased surface area results in increased reactivity to the microenvironment and greater speed of release of the compounds they carry. ${ }^{61-63}$ However, an exception to this principle is that, among particles of less than $50 \mathrm{~nm}$ diameter, larger NPs have longer circulatory half-lives. ${ }^{64,65}$ NPs can be spherical, discoidal, tubular or dendritic. ${ }^{61,63}$ The impact of NP shape on uptake and clearance has also been revealed, ${ }^{66,67}$ for instance, spheres endocytose more easily, ${ }^{20}$ while micelles and filomicelles target aortic macrophages, B cells, and natural killer (NK) cells in the immune system more effectively than polymersomes. ${ }^{68}$ In terms of charge, cationic NPs are more likely to interact with cells than negatively charged or neutral particles because the mammalian cell membrane is negatively charged. ${ }^{62}$ As a result, positively charged particles are reported to be more likely to destabilize blood cell membranes and cause cell lysis. ${ }^{61}$ Additionally, the rate of drug release is largely determined by the diameter of the pore. Motivated by the idea, Palma-Chavez et al developed a multistage delivery system by encapsulating PLGA NPs in micron-sized PLGA outer shells. ${ }^{69}$

Some types of NPs, such as micelles, possess coreshell morphological structures: a core composed of hydrophobic block segments is surrounded by hydrophilic polymer blocks in a shell that stabilizes the entire micelle. The core provides enough space to accommodate compounds, while the shell protects drug molecules from hydrolysis and enzymatic degradation. ${ }^{36}$ Surface chemical composition largely governs the chemical interactions between NPs and molecules in the body. Appropriate surface coatings can create a defensive layer, protect encapsulated cargo, and affect biological behaviors. Coating with inert polymers like polyethylene glycol (PEG) is the most commonly used method, which hinders interactions with proteins, alters the composition of the protein corona, attenuate NP recognition by opsonins which tag particles for phagocytosis, and extend the half-life of particles. ${ }^{36,70}$ Additionally, PEG coating helps the therapeutic agents reach ischemic sites, because PEGylated macromolecules tend to diffuse in the interstitial space of the heart. ${ }^{71}$ Functionalization of gangliosides can further attenuate the immunogenicity of PEGylated liposomes without damaging therapeutic efficacy. ${ }^{72}$ Removal of detachable PEG conjugates in the microenvironment of the target sites improves capture by cells. Wang and colleagues synthesized PDA-coated tanshinone IIA NPs by spontaneous hydrophobic self-assembly. ${ }^{73}$ Polyethyleneimine (PEI) is capable of condensing nucleic acid and overcoming hamper of cell membrane. Therefore, modification with PEI is mainly used for the transport of DNA and RNA. ${ }^{74}$ Of note, despite their inertness, novel NPs composed of metals can also be modified with compounds such as PEG, thiols, and disulfides. ${ }^{48,75}$ Hydrogels mixed with peptide-coated Au NPs attain greater viscosity than hydrogels mixed with Au NPs. ${ }^{24}$

Targeted delivery is a primary goal in the development of nanocarriers. Passive targeting is based on enhanced permeability in ischemic heart tissue, which does not meet the needs of clinical application. ${ }^{76}$ This fact has prompted work on targeting agent modification and magnetic guidance. Conjugation with specific monoclonal antibodies is a feasible method for delivering drug payloads targeted to ischemic lesions. Copper sulfide (CuS) NPs coupled to antibodies targeting transient receptor potential vanilloid subfamily 1 (TRPV1), permit specific binding to vascular smooth muscle cells (SMCs), and can also act as a switch for photothermal activation of TRPV1 signaling. ${ }^{52}$ In another study conducted by Liu and colleagues, two types of antibodies, binding CD63 (expressed on the surface of exosomes) or myosin light chain (MLC, expressed on injured CMs) are utilized to allow NPs to capture exosomes and accumulate in ischemic heart tissue. These NPs have a unique structure comprising an ferroferric oxide core and PEG-decorated silica shell, which simultaneously enables magnetic manipulation and molecule conjugation via hydrazone bonds. ${ }^{21}$ Targeted peptides such as atrial natriuretic peptide (ANP), ${ }^{43}$ S2P peptide (plague-targeting peptide), ${ }^{77}$ and stearyl mannose (type 2 macrophage-targeting ligand $)^{16}$ allow NPs to precisely target atherosclerotic tissue and ischemic heart lesions. Modification with EMMPRIN-binding peptide (AP9) has been shown to enable more rapid uptake of micelles by H9C2 myoblasts and primary CMs and to deliver drug payloads targeted to lesions in vivo. ${ }^{78,79}$ Another strategy for targeted nanocarriers is to produce cell mimetic carriers. Using the inflammatory response as a marker after $\mathrm{MI},{ }^{76}$ Boada and colleagues synthesized biomimetic NPs (leukosomes) by integrating membrane proteins purified from activated $\mathbf{J} 774$ macrophages into the phospholipid bilayer of NPs. Local chronic inflammatory lesions 
demonstrated overexpression of adhesion molecules, which bound leukosomes efficiently. ${ }^{80}$

\section{The Biocompatibility of Nanoparticles}

The biocompatibility of NPs is difficult to predict because any interaction with molecules or cells can cause toxic effects. Generally, NPs remain in blood, but can also extravasate from vasculature with enhanced permeability, or accumulate in the mononuclear phagocyte system. ${ }^{81}$ Important causes of NP-associated toxicity include: oxidative stress injury and cell apoptosis secondary to the production of free radicals, lack of anti-oxidants, phagocytic cell responses, and the composition of some types of particles. ${ }^{61}$ Hepatotoxicity, nephrotoxicity and any other potential off-target organ damage caused by accumulation of particles, especially those with poor degradability and slow clearance, are also essential to explore in toxicity tests. $^{82}$ Additionally, the evaluation of evoked immune responses according to the expression of inflammatory factors and stimulation of leukocytes in cell lines and animal models is also important. ${ }^{83}$

A few studies have reported NP-associated acute and chronic hazards in pharmacological applications, although some of these observations may be contentious. Specifically, aggregation of non-functionalized carbon nanotubes (CNTs) has been observed owing to inherent hydrophobicity of these particles. ${ }^{61}$ Aside from inflammation and $\mathrm{T}$ lymphocyte apoptosis, multi-walled CNTs can rupture cell membranes, resulting in macrophage cytotoxic effects. ${ }^{84,85}$ Silica NPs induce vascular endothelial dysfunction and promoted the release of proinflammatory and procoagulant factors, mediated by miR-451a negative regulation of the interleukin 6 receptor/signal transducer and activator of transcription/transcription factor (IL6R/STAT/TF) signaling pathway. ${ }^{86-88}$ Metal NPs, such as $\mathrm{Au}$ and Ag, can also penetrate the cell membrane, increase oxidative stress and decrease cell viability. ${ }^{89,90}$ Consequently, exposure to $\mathrm{Au}$ may cause nephrotoxicity ${ }^{91}$ and reversible cardiac hypertrophy. ${ }^{92}$ El-Hussainy and colleagues observed myocardial dysfunction in rats given alumina NPs. ${ }^{93,94}$ Nemmar and colleagues investigated the toxicity of ultrasmall superparamagnetic iron oxide nanoparticles (SPIONs) administered intravenously, which resulted in cardiac oxidative stress and DNA damage as well as thrombosis. ${ }^{95}$ Cellderived exosomes and a majority of natural polymers are considered relatively safe ${ }^{83}$ however, Babiker and colleagues demonstrated that dendritic polyamidoamine NPs compromise recovery from ischemia/reperfusion (I/R) injury in isolated rat hearts. ${ }^{96}$ The effects of degradation byproducts are also of concern. ${ }^{83}$ An advantage of the nanoscale size of NPs is that their injection is unlikely to block the microvascular system; however, it remains controversial whether NPs give rise to arrhythmias. ${ }^{97}$ These factors highlight that examining the biocompatibility of NPs both in vitro and in vivo is a vital component of preclinical or clinical research.

NP toxicity depends on many parameters, including material composition, coating, size, shape, surface charges and concentration. ${ }^{39}$ For instance, larger particles seem to be more favorable from a toxicology standpoint. ${ }^{83}$ However, single-walled CNTs are considered more harmful than multi-walled CNTs, due to their smaller size resulting in less aggregation and increased uptake by macrophages. ${ }^{61}$ Cationic AuNPs are more toxic compared with anionic AuNPs, which appear to be nontoxic. ${ }^{98}$ Generally speaking, NP-associated toxicity can be lowered by functionalization with nontoxic surface molecules, stabilization and localization in the region of interest by using scaffolds. ${ }^{24,99}$ The toxicity of CNTs mediated by oxidative stress and inflammation was reduced using these strategies in several studies. ${ }^{24,100}$ Local application and targeted delivery also enabled dose reduction and concurrently decreased the incidence of adverse effects. Administration of therapeutic agents directly into the infarcted or peri-infarcted myocardium is a conventional approach with a low risk of inducing embolization.

\section{The Advanced Nanotherapeutic Strategies for Myocardial Infarction} The Advanced Drug Delivery Nanocarriers

NP is a suitable method for the administration of therapeutic agents in terms of the minimization of side effects, enhanced stability of cargo, and possibility of controlled delivery and release. ${ }^{76}$ Detailed information on the experimental design and results of the latest studies on the use of NPs as therapeutic vectors are provided in Table 1. Recently, several drugs approved for clinical use as immunosuppressants have been suggested as potentially effective cardioprotective agents. For example, NPs containing cyclosporine A inhibited apoptosis and inflammation in ischemic myocardium by improving mitochondrial function. ${ }^{25,101}$ Commercial methotrexate also showed minor cardioprotective effects; additionally, when loaded into lipid core NPs, adenosine bioavailability and echocardiographic and morphometric results were all improved 


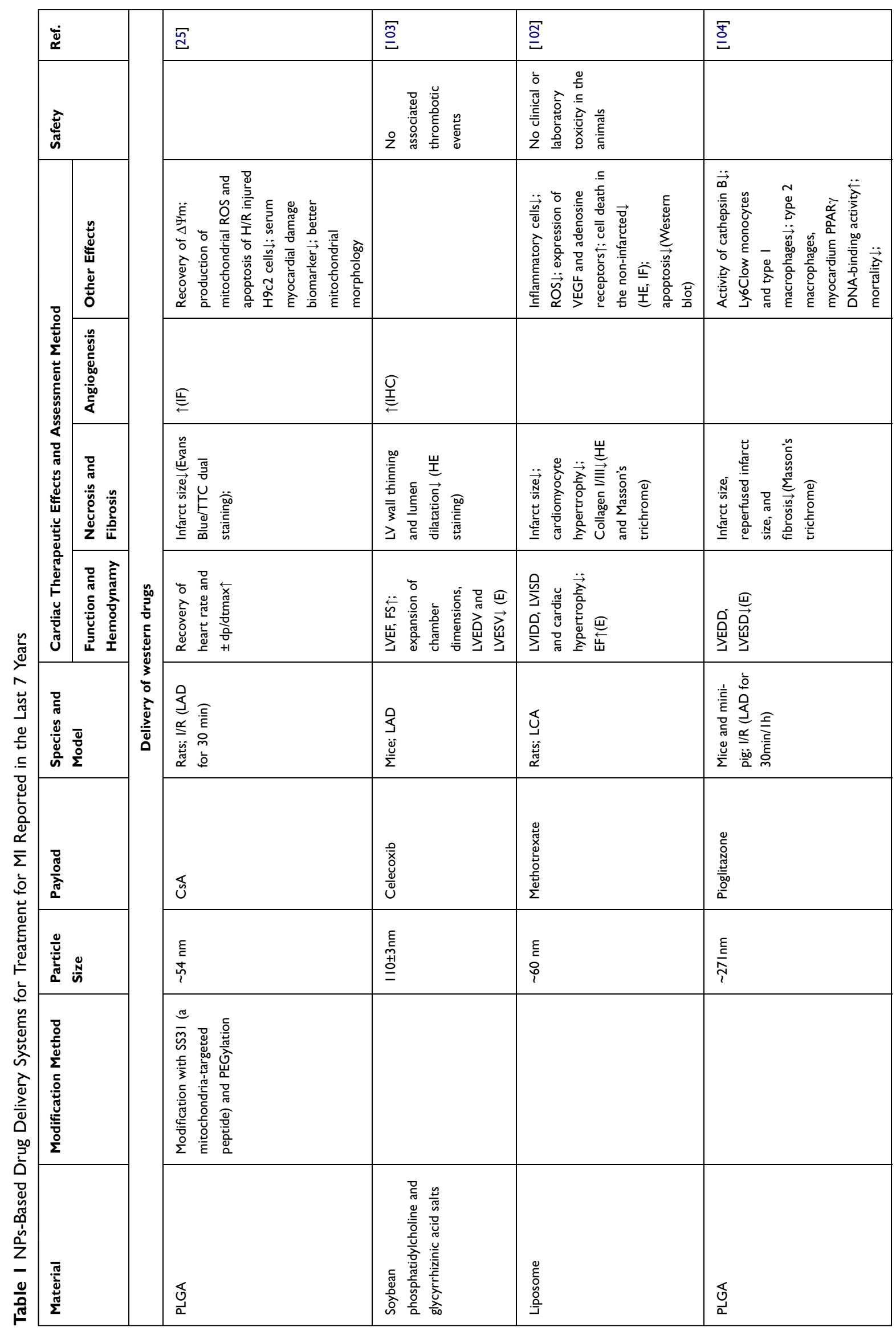




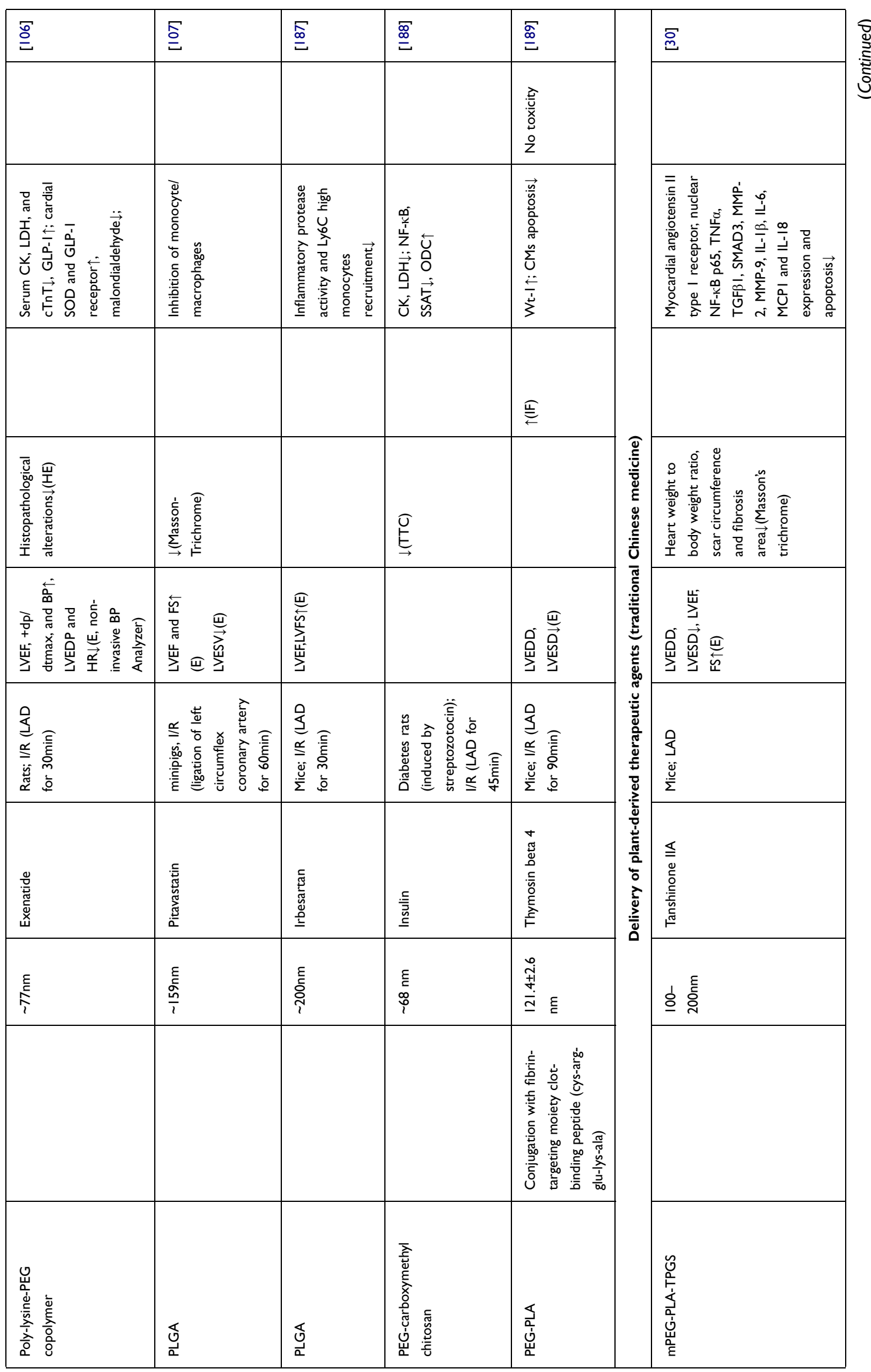




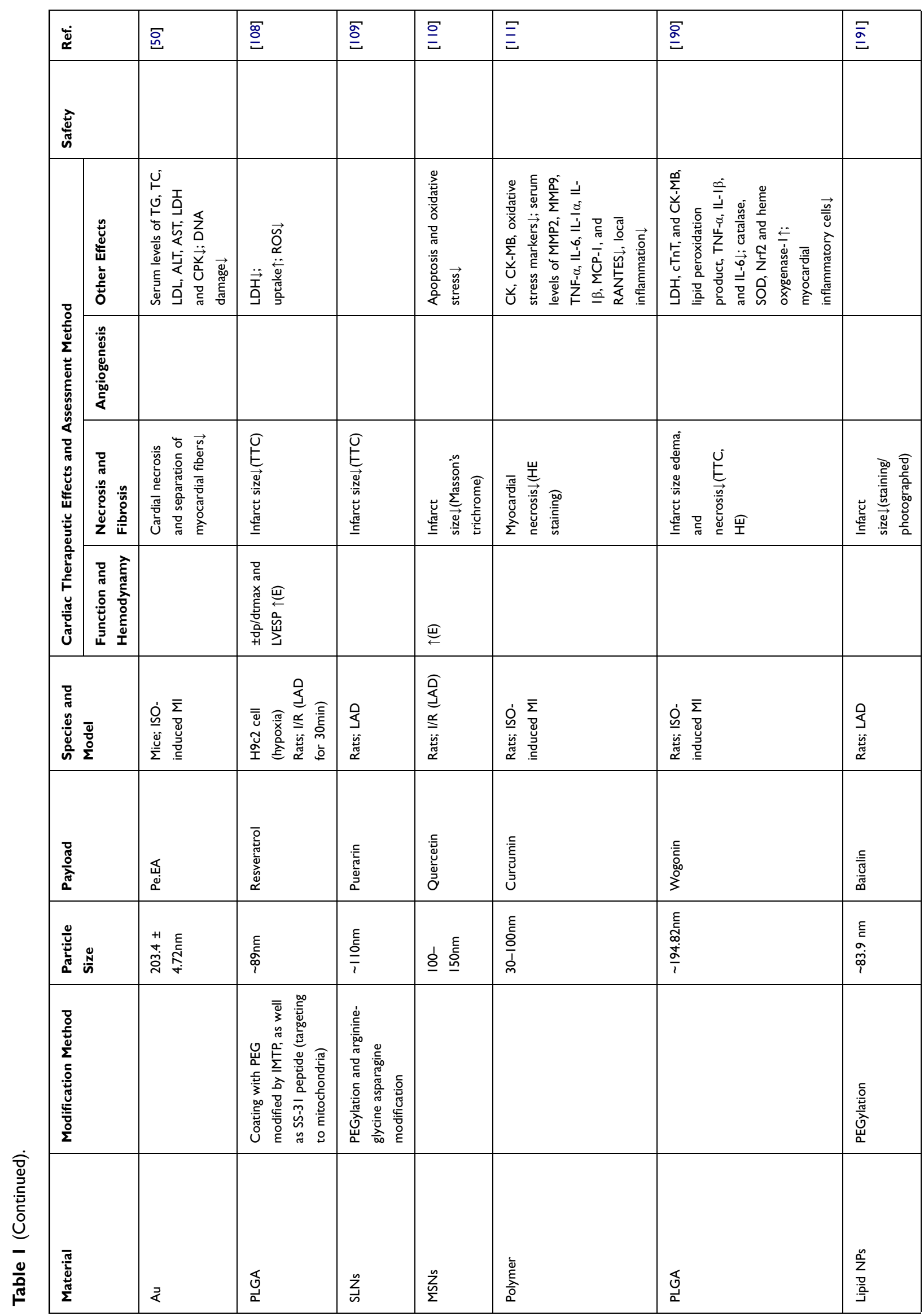




\begin{tabular}{|c|c|c|c|}
\hline$\underset{\sigma}{\sigma}$ & $\stackrel{\bar{\sigma}}{\underline{\varrho}}$ & $\underset{g}{g}$ & $\stackrel{\sqrt[\Omega]{2}}{2}$ \\
\hline \multicolumn{4}{|c|}{ 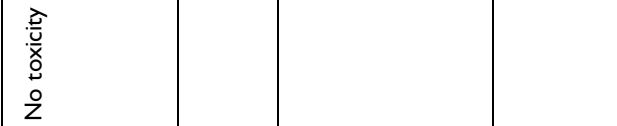 } \\
\hline & & 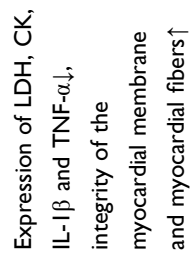 & 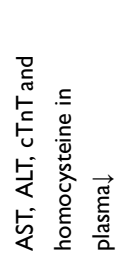 \\
\hline 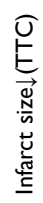 & 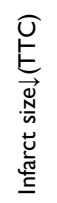 & 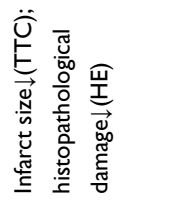 & \\
\hline
\end{tabular}

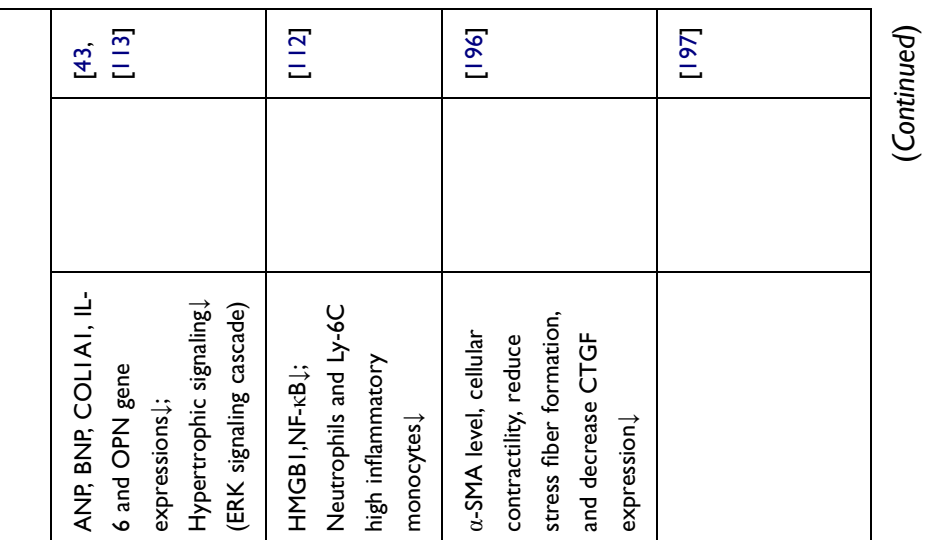

\begin{tabular}{|c|c|c|c|}
\hline 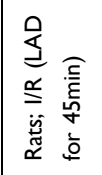 & 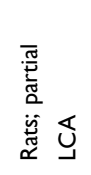 & 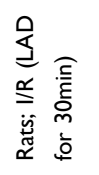 & 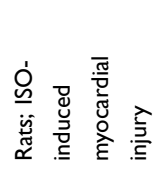 \\
\hline
\end{tabular}

\begin{tabular}{|c|c|c|c|}
\hline 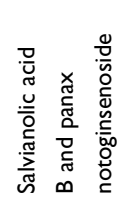 & 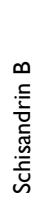 & 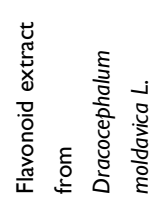 & 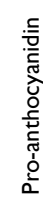 \\
\hline 으 홓 & 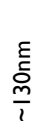 & 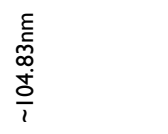 & 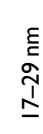 \\
\hline
\end{tabular}

\begin{tabular}{|c|c|c|c|}
\hline 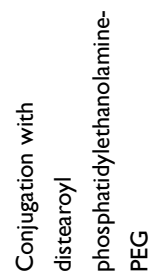 & 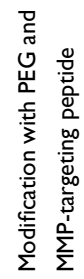 & & \\
\hline 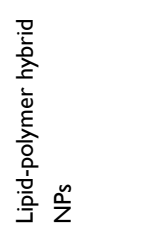 & $\sum_{u}^{n}$ & $z_{\vec{n}}^{n}$ & $z$ \\
\hline
\end{tabular}

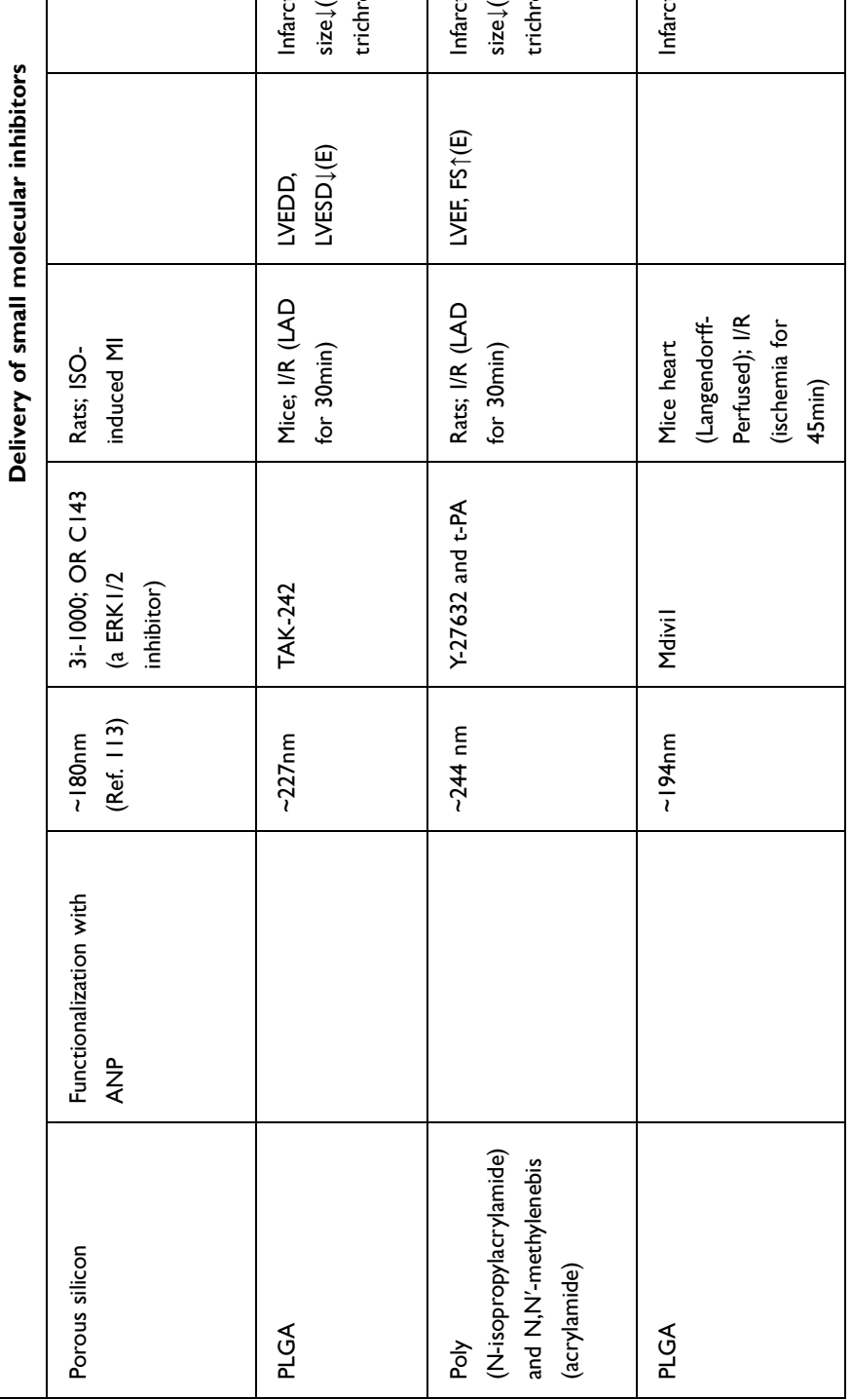




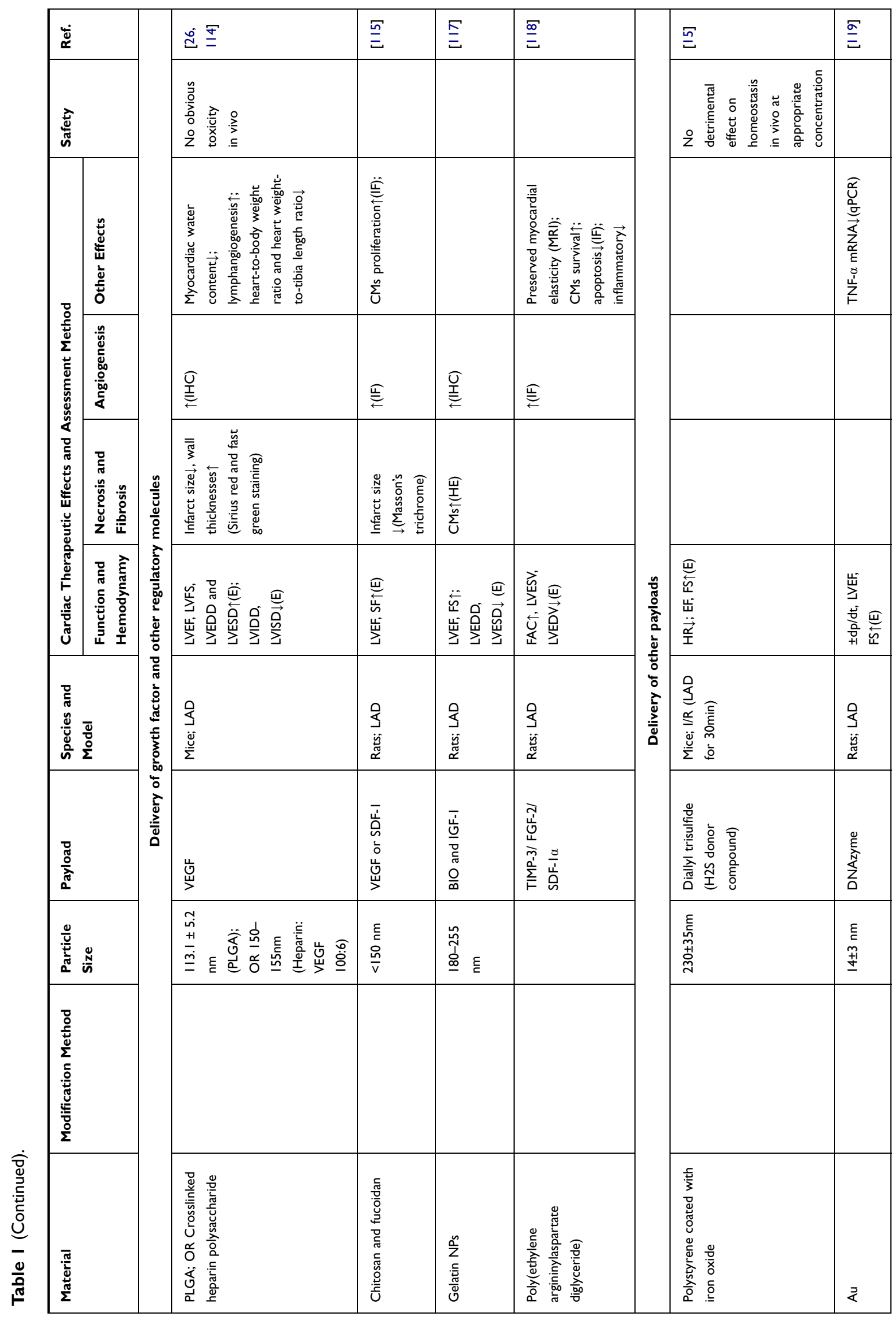




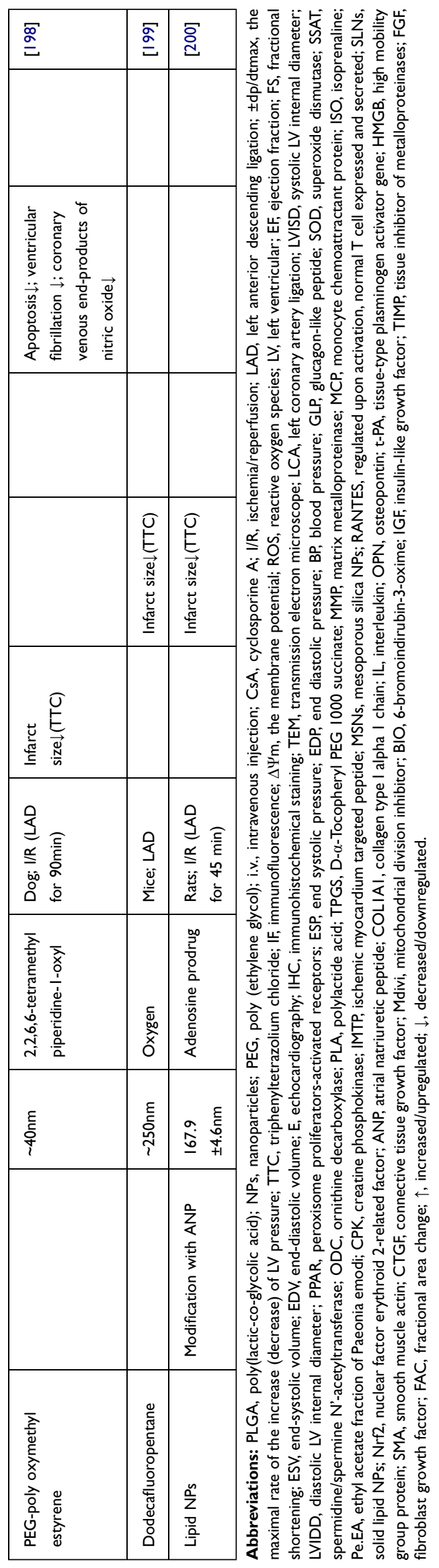

a rats model of MI. ${ }^{102}$ Margulis and colleagues developed a method to fabricate NPs via a supercritical fluids setup, which loaded and transferred celecoxib, a lipophilic nonsteroidal anti-inflammatory drug, into the NPs. These celecoxib-containing NPs alleviated ejection function damage and ventricular dilation by inducing significant levels of neovascularization. ${ }^{103}$ Furthermore, a series of investigations indicated that drugs used for hypoglycemia (eg pioglitazone, exenatide and liraglutide $)^{104-106}$ and lipid lowering (statins) ${ }^{107}$ attenuate the progression of post-MI heart failure, and are therefore also potential therapeutic cargoes for NPs in the treatment of MI.

NP systems also offer an alternative method for delivering plant-derived therapeutic agents, most of which belong to traditional Chinese medicine. It's of vital importance because of the criticization on adverse reactions caused by direct injection of such complexes. Cheng and colleagues designed a dual-shell polymeric NP as a multistage, continuous, targeted vehicle of resveratrol, a reactive oxygen species (ROS) scavenger. Due to the severe oxide stress in areas of infarction, the proposed antioxidant-delivery NPs represent a new method to effectively treat MI. These NPs are modified with two peptides, targeting ischemic myocardium and mitochondria, respectively; cardioprotective effects have been confirmed in both hypoxia/reoxygenated (H/R) H9C2 cells and $\mathrm{I} / \mathrm{R}$ rats. ${ }^{108}$ In addition, Dong and colleagues also demonstrated that puerarin-SLNs produced smaller areas of infarction in a MI rat model, evaluated by 2,3,5-triphenyltetrazolium chloride (TTC) staining. These particles were modified with cyclic arginyl-glycyl-aspartic acid peptide, a specific targeting moiety to $\alpha \mathrm{v} \beta 3$ integrin receptors, which are highly expressed on endothelial cells (ECs) during angiogenesis. ${ }^{109}$ In a recent study, quercetin was loaded into mesoporous silica NPs, which enhanced the inhibition of cell apoptosis and oxidative stress, improving ventricular remodeling and promoting the recovery of cardiac function by activating the janus kinase 2 (JAK2)/ STAT3 pathway. ${ }^{110}$ Similarly, curcumin-polymer NPs, administered by gavage, improved serum inflammatory cytokine levels compared with direct administration of curcumin. ${ }^{111}$

Translation of novel bioactive agents into clinical practice has been limited, owing to lack of sufficient bioavailability and systemic toxicity. ${ }^{76}$ Encapsulating small molecules such as 3i-1000 (an inhibitor of the GATA4NKX2-5 interaction), ${ }^{43}$ TAK-242 (inhibitor of toll-like receptor 4, TLR4) ${ }^{112}$ and C143 (inhibitor of ERK1/2) ${ }^{113}$ 
in NPs promotes myocardial repair after MI without the risk of uncontrolled and off-target adverse effects. Administration of vascular endothelial growth factor (VEGF) causes elevated vascular permeability and tissue edema. The cardioprotective effects of VEGF-loaded polymeric NPs injected either intravenously ${ }^{114}$ or intramyocardially ${ }^{115}$ eliminated vascular leakage due to promotion of lymphangiogenesis. Further studies have confirmed these results and add to the evidence that combined delivery of VEGF with other growth factors is recommended, since VEGF primarily drives the formation of new capillaries. ${ }^{116}$ Furthermore, in line with previous research, similar therapeutic effects have been demonstrated in studies using polymeric NPs loaded with stromal cell derived factor 1 (SDF-1) and insulin-like growth factor 1 (IGF-1). ${ }^{117,118}$

We also notice that some novel payloads in NPs-based therapy for MI have been studied. For example, deoxyribozyme-AuNP can silence tumor necrosis factor- $\alpha$ (TNFa). ${ }^{119} \mathrm{~A}$ target that is implicated in irreversible heart damage after MI; its effects are mediated by free radical production, downregulation of contractile proteins, and initiation of pro-inflammatory cytokine cascades. Mesoporous iron oxide NPs containing the hydrogen sulfide donor compound diallyl trisulfide act as a platform for the controlled and sustained release of this therapeutic gas molecule. The application of these NPs at appropriate concentrations, resulted in the preservation of cardiac systolic performance without any observable detrimental effects on homeostasis in vivo. ${ }^{15}$

With increasing insight into the molecular mechanisms of MI, a particular emphasis on gene therapy has emerged. Gene expression can be modulated by DNA fragments, messenger RNA (mRNA), microRNA (miRNA) and small interfering RNA (siRNA), which thus represent new approaches for treating ischemia. Currently available nucleic acid delivery systems are mainly divided into viral and non-viral systems. However, virus-based approaches are limited by their potential for uncontrollable mutagenesis. $^{36}$ From a clinical point of view, NP represents a suitable choice as novel non-viral nucleic acid vector, which could feasibly transfect in a stable, targeted, and sustained manner (as shown in Table 2).

As a common gene vehicle, plasmids face the risk of being destroyed by DNase and immunoreactivity in the serum, and transduction in non-target organs. ${ }^{120}$ A recent study by Kim and colleagues aligns with current research trends focused on virus-free therapies, in which carboxymethylcellulose NPs were designed to transfer 5-azacytidine to halt proliferation, and deliver plasmid DNA containing GATA4, myocyte enhancer factor $2 \mathrm{C}$ (MEF2C), and TBX5 to induce reprogramming and cardiogenesis of mature normal human dermal fibroblasts. ${ }^{121}$ In a methodological study, lipidoid NPs were used to successfully deliver pseudouridine-modified mRNA, encoding enhanced green fluorescent protein. ${ }^{122}$

MiRNAs act as essential regulators of cellular processes through post-transcriptional suppression; increasing evidence reveals miRNAs play critical roles in cardiovascular diseases. An miRNA-transferring platform with selfaccelerating nucleic acid release, containing a heparin core and an ethanolamine-modified poly(glycidyl methacrylate) shell, has been constructed and used as an efficient vector of miR-499, which inhibits cardiomyocyte apoptosis. ${ }^{123}$ Intravenous administration of anionic hyaluronan-sulfate NPs (mean diameter $130 \mathrm{~nm}$ ) enable the stable delivery of miR-21 mimics, thus modulating the expression of $\mathrm{TNF} \alpha$, transforming growth factor (TGF) $\beta$, and suppressor of cytokine signaling 1 (SOCS1). Consequently, these NPs switch the phenotype of macrophages from proinflammatory to reparative, promote neovascularization and reduced collagen deposition. ${ }^{124}$ Interestingly, silencing miR-21 using antagomiR-21a-5p in a nanoparticle formulation has also been shown to reduce expression of proinflammatory cytokines in vitro, and attenuate inflammation and fibrosis in mice with autoimmune myocarditis. ${ }^{125}$ A number of other potentially therapeutic miRNAs have also been successfully transferred to CMs in recent works, including miR-146a, miR-146b-5p, miR-181b, miR-1993p, miR-214-3p, miR-194-5p and miR-122-5p. ${ }^{126-128}$ Evaluation of angiogenesis, cardiac function, and scar size in these studies indicated that injectable miRNANPs can deliver miRNA to restore injured myocardium efficiently and safely. Yang and colleagues developed an in vivo miRNA delivery system incorporating a shearthinning hydrogel and NPs characterized by surface presence of miRNA and cell-penetrating peptide (CPP). ${ }^{126}$ Additionally, angiotensin II type 1 receptor-targeting peptide-modified NPs serve as targeted carriers for anti-miR-1 antisense oligonucleotide, significantly reducing apoptosis and infarct size. $^{129}$

SiRNAs inhibit gene expression by mediating mRNA cleavage in a sequence-specific manner, highlighting NPbased RNA interference as another viable approach to modulate cellular phenotype and attenuate cardiac failure. Dosta and colleagues demonstrated that $\operatorname{poly}(\beta$-amino ester) 
Table 2 NPs-Based Nucleic Acid Delivery Systems for Treatment for MI Reported in the Last 7 Years

\begin{tabular}{|c|c|c|c|c|c|c|c|}
\hline $\begin{array}{l}\text { Material and } \\
\text { Modification } \\
\text { Method }\end{array}$ & $\begin{array}{l}\text { Particle } \\
\text { Size }\end{array}$ & Payload & $\begin{array}{l}\text { Species } \\
\text { and } \\
\text { Model }\end{array}$ & $\begin{array}{l}\text { Delivery } \\
\text { Method }\end{array}$ & Therapeutic Effects & $\begin{array}{l}\text { Safety } \\
\text { in vivo }\end{array}$ & Ref. \\
\hline \multicolumn{8}{|c|}{ DNA/modRNA delivery system } \\
\hline $\begin{array}{l}\text { Epoxide-derived } \\
\text { lipidoid complex } \\
(\mathrm{CI} 4-\mathrm{I} \text { I38) }\end{array}$ & $\begin{array}{l}\sim 155 \mathrm{~nm} \\
\text { diameter }\end{array}$ & $\begin{array}{l}\text { eGFP } \\
\text { modRNA }\end{array}$ & $\begin{array}{l}\text { Rats, LAD; } \\
\text { Pigs, } \\
\text { embolic } \\
\text { coil after } \\
\text { balloon } \\
\text { occlusion }\end{array}$ & $\begin{array}{l}\text { Intramyocardial } \\
\text { injection; } \\
\text { ascending aorta } \\
\text { (pig only) }\end{array}$ & eGFP expression $\uparrow$ & $\begin{array}{l}\text { No obvious } \\
\text { cytotoxicity }\end{array}$ & {$[122]$} \\
\hline $\begin{array}{l}\text { Bioreducible } \\
\text { dendrimer } \\
\text { polymer }\end{array}$ & & $\begin{array}{l}\text { HRI (a } \\
\text { plasmid) }\end{array}$ & $\begin{array}{l}\text { Rats; I/R } \\
\text { (LAD for } \\
30 \mathrm{~min} \text { ) }\end{array}$ & $\begin{array}{l}\text { Infarct and peri- } \\
\text { infarct area } \\
\text { injection }\end{array}$ & $\begin{array}{l}\text { LVEF, coronary artery stroke } \\
\text { volume, CO, hemodynamic } \\
\text { function } \uparrow(E) \text {; Fibrosis } \downarrow\end{array}$ & & {$[201]$} \\
\hline \multicolumn{8}{|c|}{ miRNA delivery system } \\
\hline Heparin@PGEA & $\sim 180 \mathrm{~nm}$ & $\begin{array}{l}\text { miR-499 (alone } \\
\text { or with } \\
\text { pVEGF) }\end{array}$ & Mice; LAD & i.v. & $\begin{array}{l}\text { LVEF/LVFS/LVIDD/LVIDS } \\
\text { improvement; Infarct size, fibrosis } \\
\text { and hypertrophy } \downarrow \text {; Angiogenesis } \uparrow \text {; } \\
\text { Apoptosis } \downarrow\end{array}$ & $\begin{array}{l}\text { No } \\
\text { evidence of } \\
\text { toxicity }\end{array}$ & {$[123]$} \\
\hline Hyaluronan-sulfate & $\sim 130 \mathrm{~nm}$ & miR-2I mimic & Mice; LCA & i.v. & $\begin{array}{l}\text { LV posterior wall and LV mass; } \\
\text { Collagen deposition } \downarrow \text {; } \\
\text { Angiogenesis } \uparrow \text {; TNF } \alpha \downarrow \text {, TGF- } \beta \text { and } \\
\text { Socs } I \uparrow\end{array}$ & & {$[124]$} \\
\hline $\begin{array}{l}\text { PFBT core with } \\
\text { a DSPE-PEG shell, } \\
\text { conjugated with } \\
\text { CPP }\end{array}$ & $\sim 110 \mathrm{~nm}$ & miR-199a-3p & $\begin{array}{l}\text { Rats; I/R } \\
\text { (ligation for } \\
\text { Ih) }\end{array}$ & $\begin{array}{l}\text { Peri-infarct area } \\
\text { injection; in } \\
\text { shear-thinning } \\
\text { hydrogel }\end{array}$ & $\begin{array}{l}\text { EF } \uparrow \text {; preserved LVESV; Scar size } \downarrow \text {; } \\
\text { Angiogenesis } \uparrow \text {; Proliferation of } \\
\text { CMs } \uparrow \text {; Expression of HIFI } \alpha \uparrow\end{array}$ & & {$[125]$} \\
\hline $\begin{array}{l}\text { Poly(amidoamine)- } \\
\text { histidine }\end{array}$ & $60 \mathrm{~nm}$ & $\begin{array}{l}\text { miR-2I4-3p, } \\
\text { miR-194-5p, } \\
\text { antagomiR- } \\
\text { I22-5p }\end{array}$ & $\begin{array}{l}\mathrm{H} 9 \mathrm{c} 2 \text { and } \\
\text { primary } \\
\text { cultured } \\
\mathrm{CMs}\end{array}$ & & $\begin{array}{l}\text { Expression levels of Bax, Bad, } \\
\text { Caspase } 3 \text { and Caspase } 9 \downarrow \text {; } \\
\text { Apoptosis } \downarrow \text {; Cell viability } \uparrow\end{array}$ & & {$[127]$} \\
\hline \multicolumn{8}{|c|}{ siRNA/ antisense oligonucleotide delivery system } \\
\hline $\begin{array}{l}\text { Dendrigraft poly- } \\
\text { L-lysine, decored } \\
\text { with ATIR- } \\
\text { targeting peptide, } \\
\text { and PEGylated }\end{array}$ & $\sim 200 \mathrm{~nm}$ & $\begin{array}{l}\text { Anti-miR-I } \\
\text { antisense } \\
\text { oligonucleotide }\end{array}$ & Mice; LAD & i.v. & Infarct size $\downarrow$ (Masson-Trichrome) & & {$[130]$} \\
\hline $\begin{array}{l}\text { PMSNs, combined } \\
\text { with PEI }\end{array}$ & $\begin{array}{l}100- \\
200 \mathrm{~nm}\end{array}$ & CCR2 siRNA & Mice; LAD & $\begin{array}{l}\text { Combined } \\
\text { therapy: } \\
\text { intramyocardial } \\
\text { injection (MSCs) } \\
\text { and i.v. (NPs) }\end{array}$ & $\begin{array}{l}\text { Infarct size } \downarrow ; \text { Angiogenesis } \uparrow \text {; Ly6C } \\
\text { high monocytes/CDI Ib-positive } \\
\text { monocytes } \downarrow\end{array}$ & $\begin{array}{l}\text { No obvious } \\
\text { toxicity }\end{array}$ & {$[|3|]$} \\
\hline $\begin{array}{l}\text { A polymer-lipid } \\
\text { hybrid material, } \\
\text { combined with } \\
\text { PEG-lipid } \\
\text { conjugates }\end{array}$ & $60-80 \mathrm{~nm}$ & siSdfI, siMcpl & $\begin{array}{l}\text { Mice; LCA } \\
\text { after I0- } \\
\text { week high- } \\
\text { fat diet }\end{array}$ & i.v. & $\begin{array}{l}\text { Preserved LV anatomy and } \\
\text { function; Infarct size and fibrosis } \downarrow \text {; } \\
\text { Bone MSCs and leukocytes } \\
\text { release } \uparrow(s i S d f I) / \downarrow \text { (siMcpI); } \\
\text { Inflammation of infarction area } \downarrow\end{array}$ & & [202] \\
\hline
\end{tabular}


Table 2 (Continued).

\begin{tabular}{|c|c|c|c|c|c|c|c|}
\hline $\begin{array}{l}\text { Material and } \\
\text { Modification } \\
\text { Method }\end{array}$ & $\begin{array}{l}\text { Particle } \\
\text { Size }\end{array}$ & Payload & $\begin{array}{l}\text { Species } \\
\text { and } \\
\text { Model }\end{array}$ & $\begin{array}{l}\text { Delivery } \\
\text { Method }\end{array}$ & Therapeutic Effects & $\begin{array}{l}\text { Safety } \\
\text { in vivo }\end{array}$ & Ref. \\
\hline Lipidoid NPs & $50 \mathrm{~nm}$ & CRMP2 siRNA & $\begin{array}{l}\text { ApoE-/- } \\
\text { mice; LCA }\end{array}$ & i.v. & $\begin{array}{l}\text { M2 polarization } \uparrow \text {; Inflammation, } \\
\text { infarct size and fibrosis } \downarrow \text {;(Masson’s } \\
\text { trichrome) } \\
\text { Post-MI heart failure and } \\
\text { mortality } \downarrow\end{array}$ & & [203] \\
\hline Lipidoid NPs & & IFR5 siRNA & $\begin{array}{l}\text { ApoE-/- } \\
\text { mice; LCA }\end{array}$ & i.v. & MMP9/TIMPI $\downarrow$; healing $\uparrow ; \mathrm{HF} \downarrow$ & & [204] \\
\hline $\begin{array}{l}\text { Arginine- } \\
\text { terminated } \\
\text { generation } 4 \\
\text { poly(amidoamine) } \\
\text { (Arg-G4) }\end{array}$ & $\begin{array}{l}152.2 \\
\pm 18.5 \mathrm{~nm}\end{array}$ & PHD2 siRNA & Mice; LCA & $\begin{array}{l}\text { Intramyocardial } \\
\text { injection of Arg- } \\
\text { G4-siRNA } \\
\text { transfected } \\
\text { MSCs }\end{array}$ & $\begin{array}{l}\text { LVEF and LVFS; Infarct area } \downarrow \text {; } \\
\text { Survival } \uparrow\end{array}$ & & [205] \\
\hline
\end{tabular}

Abbreviations: eGFP, enhanced green fluorescent protein; PGEA, ethanolamine-modified poly(glycidyl methacrylate); PFBT, poly(9,9-dioctylfluorene-alt-benzothia-diazole); DSPE, I.2-distearoyl-sn-glycero-3-phosphoethanolamine; CPP, cell-penetrating peptide; PMSNs, photoluminescent mesoporous silicon nanoparticles; PEI, polyethylenimine; MSC, mesenchymal stem cell; ATIR, angiotensin II type I receptors; SdfI, stromal-derived factor I; CRMP, collapsin response mediator protein; HRI, human Relaxinexpressing plasmid DNA with hypoxia response element 12 copies; IRF5, interferon regulatory factor 5; CO, cardiac output.

particles modified by adding lysine-/histidine-oligopeptides could represent a system for the transfer of siRNA. ${ }^{130}$ Studies have now revealed that chemokine $\mathrm{C}-\mathrm{C}$ motif ligand 2 (CCL2) and its cognate receptor $\mathrm{C}-\mathrm{C}$ chemokine receptor 2 (CCR2) promoted excessive Ly6 $\mathrm{C}^{\text {high }}$ inflammatory monocyte infiltration in infarcted area and aggravate myocardial injury. ${ }^{131}$ Photoluminescent mesoporous silicon nanoparticles (MSNPs) carrying siCCR2 have been reported to improve the effectiveness of transplanted mesenchymal stem cells (MSCs) in reducing myocardial remodeling after acute MI. ${ }^{131}$ Targeted transportation and enhanced uptake with minimum leakage improved the efficiency of delivery via NPs, significantly outperforming the control group. Taken together, these studies demonstrate that NPs act as promising drug delivery systems in the treatment of MI.

\section{Enhancement of Cardiac Engineering Biomaterials by Nanoparticles}

Myocardial patches and scaffolds, consisting of either bioactive hydrogels or nanofibers, are minimally invasive, relatively localized, and targeted approaches to repair the heart after IHD. Those biomaterials must have an anisotropic structure, mechanical elasticity, electrical conductivity, and the ability to promote ischemic heart repair. ${ }^{132}$ A variety of NPs have been applied in this field, among which inorganic NPs have been the focus of most research efforts. ${ }^{42}$ These investigations of inorganic NPs can be divided into four categories based on their effects and the mechanisms involved, which are described in this section.

NPs enhance physical properties and electroconductivity, which is essential for the biomaterials to properly accommodate cardiac cells and subsequently resulted in cell retention, cell-cell coupling and robust synchronized beating behavior. CNTs are able to increase the required physical properties of scaffolds, such as maximum load, elastic modulus, and toughness. ${ }^{133,134}$ Gelatin methacrylate (GelMA) also has decreased impedance, hydrogel swelling ratio, and pore diameter, as well as increased Young's modulus when combined with gold nanorods (AuNRs). ${ }^{135}$ Given this insight, highly electroconductive NPs have been increasingly investigated. ${ }^{34,99}$ Specifically, Ahadian and colleagues revealed that a higher integrated CNT concentration in gels resulted in greater conductivity. ${ }^{136}$ Zhou and colleagues verified the therapeutic effects of patches incorporating single-walled CNT for myocardial ischemia, which halted progressive cardiac dysfunction and regenerated the infarcted myocardium. ${ }^{137}$ Spherical AuNPs have also been shown to increase the conductivity of chitosan hydrogels in a concentration-dependent manner. ${ }^{138}$ Interestingly, silicon NPs mimic the effects of AuNRs without affecting conductivity or stiffness, as reported by Navaei and colleagues. $^{139}$ 
Several studies demonstrate the effects of CNT on CM functions. When CMs are cultured on multi-walled CNT substrates or treated with CNT-integrated patches, these cells show spontaneous electrical activity. ${ }^{34,99,140}$ Brisa and colleagues functionalized reverse thermal gels with AuNPs, investigating the phenotype of CMs in vitro; the growth of cells with a CM phenotype was observed, along with gap junction formation. ${ }^{141} \mathrm{CMs}$ exposed to AuNRcontaining GelMa show higher affinity, leading to packed and uniform tissue structure. ${ }^{135}$ These conductive scaffolds also facilitate the robustness and synchrony of spontaneous beating in CMs without damaging their viability and metabolic activity.

Combined incorporation of inorganic NPs and cells represents a feasible strategy to promote therapeutic effects. Despite some reports on the cytotoxicity of $\mathrm{Au},{ }^{89,90}$ no significant loss of viability, metabolism, migration, or proliferation of MSCs in scaffolds containing AuNP is reported. A CNT-embedded, electrospun chitosan/polyvinyl alcohol mesh is reported to promote the differentiation of MSCs to CMs. ${ }^{142}$ In another approach, Baei and colleagues added AuNPs to chitosan thermosensitive hydrogels seeded with MSCs. ${ }^{138}$ There was a significant increase in expression of early and mature cardiac markers, indicating enhanced cardiomyogenic differentiation of MSCs compared to the matrix alone, while no difference in growth was observed. Gao et al created a fibrin scaffold, in which cells and AuNPs were suspended simultaneously; these bioactive patches were shown to promote left ventricular function and decrease infarct size and apoptosis in the periscar boarder zone myocardium in swine models of acute MI. ${ }^{97}$ These studies of AuNP-containing scaffolds demonstrated reduced infarct and fibrotic size, as well as facilitated angiogenesis and cardiac function, which can be attributed at least in part to the enhanced expression of connexin 43 and atrial natriuretic peptide, and activation of the integrin-linked kinase(ILK)/serine-threonine kinase (p-AKT)/GATA4 pathway. ${ }^{49,143,144}$ Scaffolds containing Ag NPs evoke M2 polarization of macrophages in vitro; ${ }^{145}$ which may also play a role in cardioprotective action because M2 macrophages are capable of promoting cardiac recovery via the secretion of anti-inflammatory cytokines, collagen deposition, and neovascularization. ${ }^{146}$

Similarly, CNT also act synergically with poly (N-isopropylacrylamide) scaffolds containing adiposederived stem cells, ${ }^{147}$ significant improvement of cardiac function and increased implantation and proliferation of stem cells has been observed with these scaffolds, compared with scaffolds without CNT. ${ }^{147}$ Selenium NPs ${ }^{148}$ and titania $\mathrm{NPs}^{53}$ have been shown to improve the mechanical and conductive properties of chitosan patches, promoting their ability to support proliferation and the synchronous activity of cells growing on these patches.

Mounting evidence demonstrates the unique benefits of using cardiac scaffolds with magnetic NPs such as SPIONs; these benefits include, but are not limited to, significant improvements in cell proliferation ${ }^{149}$ and assembly of electrochemical junctions. ${ }^{150}$ Given that magnetic manipulation enhances the therapeutic efficacy of iron oxide NPs in cardiac scaffolds, Chouhan and colleagues designed a magnetic actuator device by incorporating magnetic iron oxide NPs (MIONs) in silk nanofibers; this resulted in more controlled drug release properties, as well as the promotion of proliferation and maturation in CMs. ${ }^{151}$ Magnetic NPs can be used to label induced pluripotent stem cell (iPSC)-derived CMs via conjugation with antibodies against signal-regulatory protein $\alpha$. Zwi-Dantsis and colleagues reported the construction of tailored cardiac tissue microstructures, achieved by orienting MIONlabelled cells along the applied field to impart different shapes without any mechanical support. ${ }^{152}$ However, the interactions between and effects of NPs and cells in scaffolds, and the cardioprotective efficacy of patches in which NP-labelled cells are suspended, require further elucidation.

Polymeric nanomaterials have also been investigated in the context of cardiac bioengineering materials; for instance, water-swollen polymer NPs have been used to prepare nanogels. With a 3D structure containing crosslinked biopolymer networks, nanogels can encapsulate, protect, and deliver various agents. ${ }^{83,153}$ PDA-coated tanshinone IIA NPs suspended in a ROS-sensitive, injectable hydrogel via PDA-thiol bonds significantly improved cardiac performance, accompanied by inhibition of the expression of inflammation factors in rat model. ${ }^{73}$ After implanting cryogel patches consisting of GelMa and linked conductive polypyrrole NPs ${ }^{154}$ or scaffolds of electrospun GelMA/polycaprolactone with GelMApolypyrrole NPs, ${ }^{155}$ left ventricular (LV) ejection fraction (EF) has been shown to increase, with a concurrent decrease in infarct size, in MI animal models.

\section{Combined Nanoparticle-Cell Strategies}

Progenitor or stem cell-based therapy in the form of injections and engineered cardiac patches, discussed in the 
previous section, has been recognized as a promising strategy to improve the cardiac niche and ameliorate adverse remodeling processes and fibrosis after acute MI. ${ }^{56,156,157}$ However, poor survival and low engraftment rates for transplanted cells are still major challenges in this field. ${ }^{157}$ Among possible optimization strategies, combining NPs with stem cell therapy is of great interest (Table 3).

Accumulating evidence has shown two main mechanisms for NP-loaded cell therapy in the context of MI treatment. Firstly, various NP types could efficiently improve survival and cell proliferation, modulating differentiation of implanted cells in the ischemic microenvironment. ${ }^{62,158}$ Specifically, electrically driven nanomanipulators could guide cardiomyogenic differentiation of MSCs: in a previous study, electroactuated gold NPs were administrated with pulsed electric field stimulation, and tube-like morphological alterations were observed, along with upregulation of cardiac specific markers. ${ }^{143}$ Adipose-derived stem cells that load PLGA-simvastatin NPs promoted differentiation of these cells into SMCs and ECs, and had cardioprotective effects in a mouse model of MI induced by left anterior descending ligation. ${ }^{17}$ Secondly, engraftment rate is another important factor affecting treatment efficacy in this context. ${ }^{159}$ Zhang and colleagues designed silica-coated, MION-labelled endothelial progenitor cells; intravenous administration of these cells in a rat model of MI significantly improved cardiac performance, as indicated by echocardiogram, morphological, and histological evidence, and neovascularization. This indicates magnetic guidance may potentially address the problem of low levels of stem cell retention, which has typically been observed. ${ }^{51}$ In particular, NPs can link the therapeutic cells to injured $\mathrm{CMs}$, thereby promoting cell anchorage and engraftment. To this end, Cheng and colleagues established a magnetic, bifunctional cell connector by conjugating NPs with two antibodies: one against cell determinant (CD)45, which is expressed on bone marrow-derived stem cells, and one against MLC. The magnetic core of this NP also enabled physical enrichment in ischemic heart tissue using external magnets. ${ }^{160}$ More than one mechanism may be involved in a study. Chen and colleagues fabricated a sustained release carrier of insulin-like growth factor (IGF), a pro-survival agent, via in situ growth of $\mathrm{Fe}_{3} \mathrm{O}_{4}$ NPs on MSNPs. In this study, the NPs promoted both the survival and retention of MSCs, and intramyocardial injection of the NP-labeled MSCs was able to ameliorate functional and histological damage without any obvious toxicity in vivo. ${ }^{161}$ However,
SPION labeling does not seem to improve therapeutic efficiency, as demonstrated by Wang and colleagues in a study using hypoxia-preconditioned SPION-labeled adiposederived stem cells (ASCs). ${ }^{162}$

\section{Application of Exosomes in MI Treatment}

Primary criticisms of cell-based therapies include their potential immunogenicity, arrhythmogenicity and tumorigenicity. It is widely accepted that the beneficial effects of cell-based therapy are mainly attributable to paracrine effects rather than directly replenishing lost $\mathrm{CMs} ;{ }^{56}$ researchers are therefore investigating of cell-free approaches. Exosomes have attractive properties including stable transport, homing to target tissues or cells, and penetration of biological barriers, as well as being more biocompatible with lower immunogenicity than cell-based approaches. Interestingly, post-MI circulating exosomes serve as important cardioprotective messengers. ${ }^{163,164}$ Manipulating their biodistribution has proven to be a viable strategy to reduce infarct size, promoting angiogenesis and ejection functions. ${ }^{21}$ However, from a therapeutic standpoint, the lack of control over endogenous exosome production and cargo encapsulation limits the use of this naturally-present mechanism for therapeutic enhancement. The low purity and weak targeting of natural exosomes are two further obstacles to overcome before clinical application. Strategies to address these include finding robust sources; optimized isolation methods for higher yields, efficiency and purity; and improving therapeutic payloads. These have been systematically summarized in other reviews. ${ }^{165-167}$

\section{Nanoparticle-Based Prevention Strategies for Myocardial Infarction}

AS is considered a low-grade, chronic inflammatory disease, characterized by accumulation and deposition of cholesterol in arteries, as well as remodeling of the extracellular matrix in the intima and inner media. ${ }^{12,168}$ Inflammation of ECs, proliferation of SMCs, and recruitment of monocytes and macrophages play a critical role in the development of AS. NPs allow for the packaging of large amounts of therapeutic compounds in a compact nanostructure, specifically targeting pathological mechanisms and attenuating atherogenesis. Optimization of the loaded drug and NP target together lead to enhanced efficacy while minimizing side effects. ${ }^{169}$ In this section, we summarize recent breakthroughs in the order of pathological progression, as shown in Table 4. 


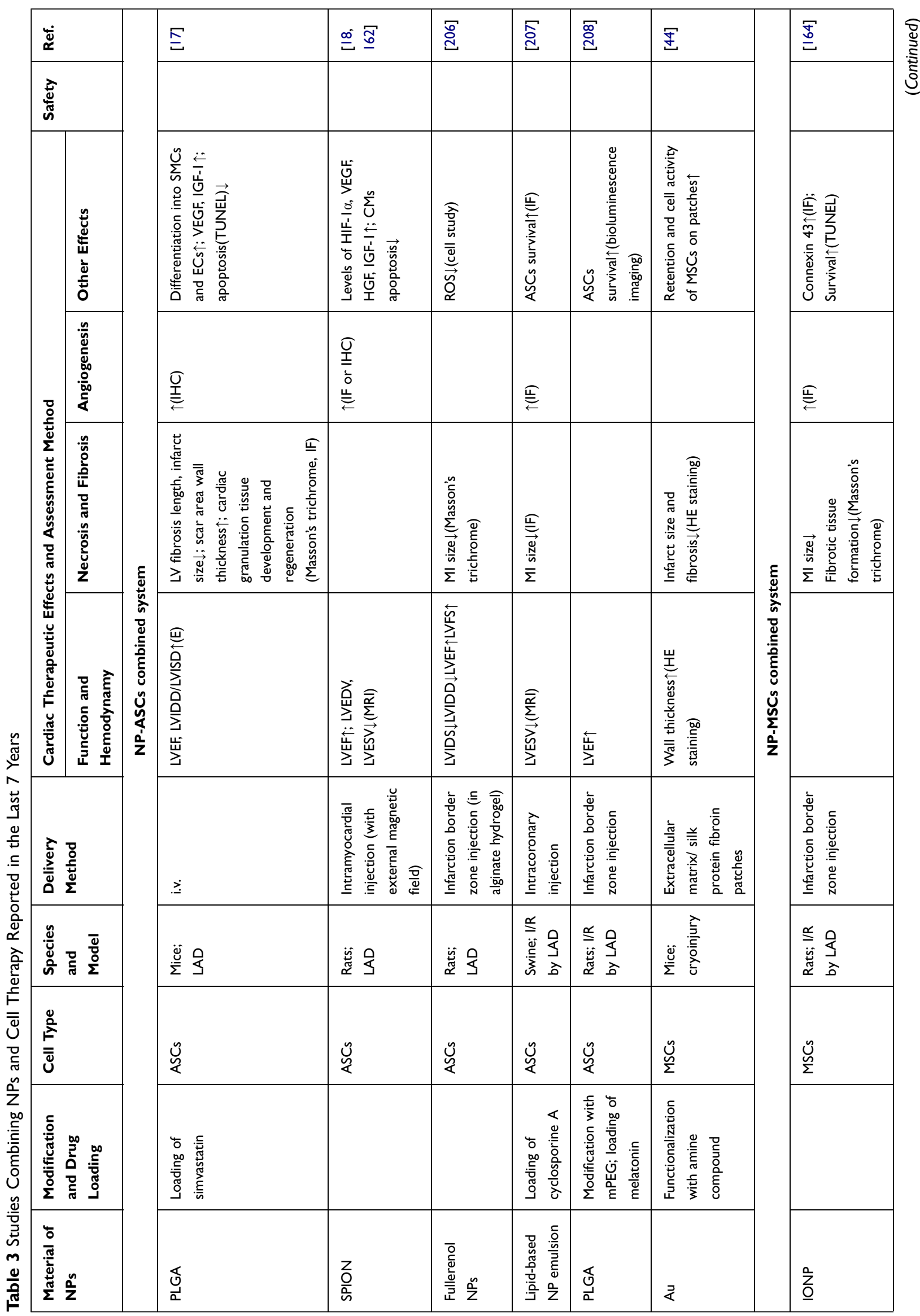




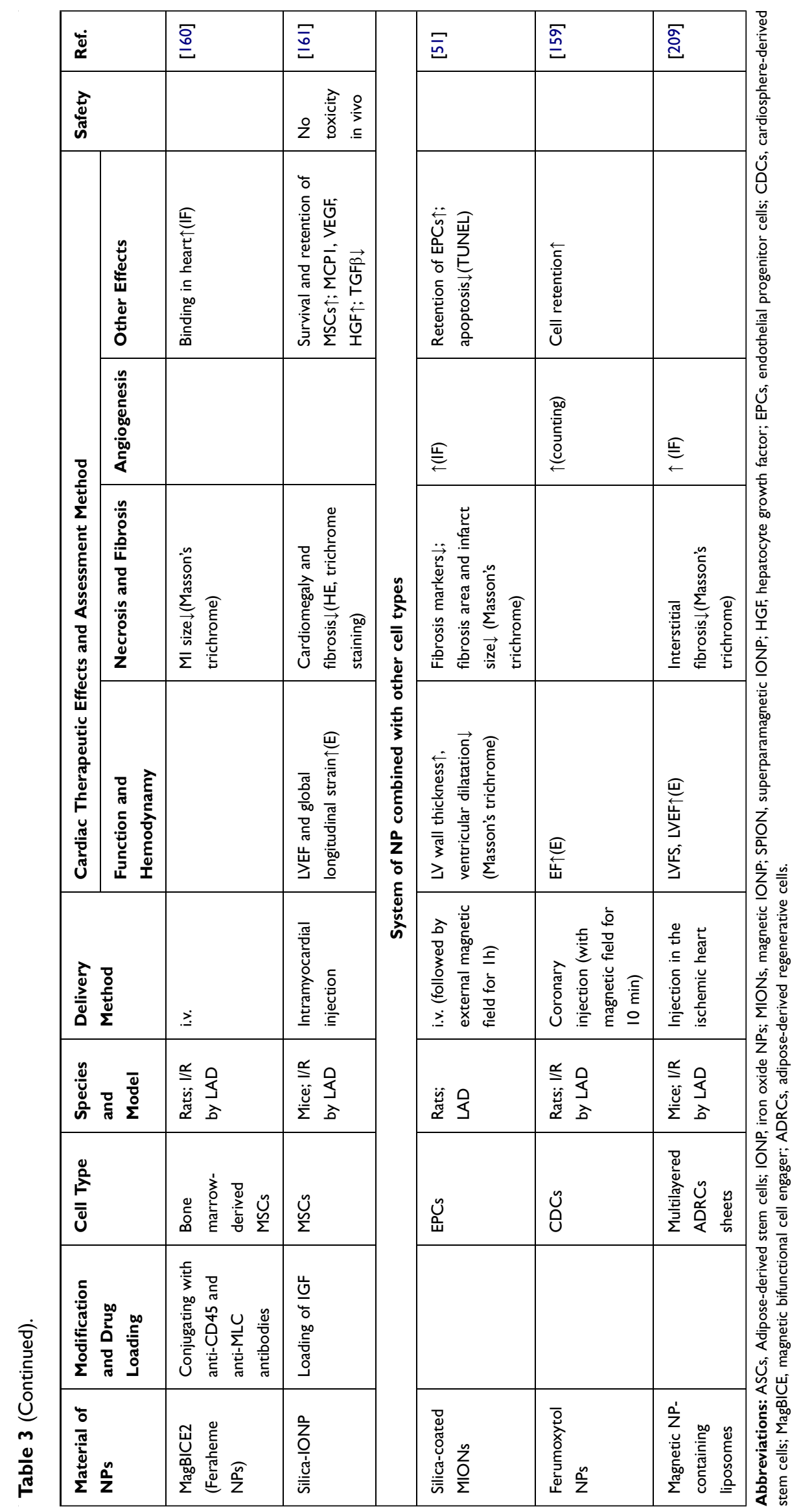


Table 4 NPs-Based Preventive Strategies for MI Reported in the Last 7 Years

\begin{tabular}{|c|c|c|c|c|c|c|}
\hline $\begin{array}{l}\text { Materials and } \\
\text { Modifications }\end{array}$ & $\begin{array}{l}\text { Particle } \\
\text { Size }\end{array}$ & Payload & Species and Model & $\begin{array}{l}\text { Therapeutic and Preventive } \\
\text { Effects }\end{array}$ & Safety & Ref. \\
\hline \multicolumn{7}{|c|}{ Primary prevention } \\
\hline PLA & $\begin{array}{l}\sim 279 \mathrm{~nm} \text { (by } \\
\text { SEM) }\end{array}$ & Aliskiren & $\begin{array}{l}\text { Spontaneously } \\
\text { hypertensive rats }\end{array}$ & $\begin{array}{l}\mathrm{BP} \downarrow ; \text { vasoactivity of mesenteric } \\
\text { artery } \\
\text { Collagen content in the aorta } \downarrow \text {; } \\
\text { Fibrosis of aortic tunica media } \uparrow \\
\text { LV total NOS and neuronal } \\
\text { NOS } \uparrow \text {; endothelial NOS } \downarrow\end{array}$ & & [29] \\
\hline $\begin{array}{l}\text { Biscarbamate- } \\
\text { crosslinked Gal-PEG } \\
\text {-PEI NPs }\end{array}$ & & AGT shRNA & $\begin{array}{l}\text { Spontaneously } \\
\text { hypertensive rats }\end{array}$ & $\begin{array}{l}\mathrm{BP} \downarrow ; \\
\text { Heart hypertrophy } \downarrow ; \text { Myocardial } \\
\text { ultrastructure improvement }\end{array}$ & & {$[172]$} \\
\hline PLGA & & $\begin{array}{l}\text { Propylene } \\
\text { glycol alginate } \\
\text { sodium sulfate }\end{array}$ & $\begin{array}{l}\text { Rats; 8-week } \\
\text { streptozotocin } \\
\text { induced diabetic } \\
\text { cardiomyopathy }\end{array}$ & $\begin{array}{l}\text { LVEF, FS } \uparrow \text {; LVISD, LVIDD } \downarrow \\
\text { Myocardial morphology } \uparrow \\
\text { Coronary microcirculation } \uparrow \\
\text { Plasminogen activator inhibitor- } \\
\text { I expression in CMs } \downarrow \text {; TNF- } \alpha \text {, } \\
\text { IL-I } \beta, \text { IL- } 6 \downarrow ; \text { NF-kb and AGEs/ } \\
\text { RAGE pathway } \downarrow \text {; serum SOD } \\
\text { and GSH } \uparrow\end{array}$ & & {$[210]$} \\
\hline Hyaluronic Acid & & Curcumin & $\begin{array}{l}\text { Hypertensive, } \\
\text { heterozygous rats }\end{array}$ & $\mathrm{BP} \downarrow$ & & [211] \\
\hline Lipid NPs & $65 \sim 75 \mathrm{~nm}$ & ApoB siRNA & Lean rhesus macaque & $\mathrm{LP}(\mathrm{a}) \downarrow$ & & {$[212]$} \\
\hline SLNs & $180-220 \mathrm{~nm}$ & $\begin{array}{l}\text { Candesartan } \\
\text { cilexetil }\end{array}$ & $\begin{array}{l}\text { Rats; oral fructose } \\
\text { solution }\end{array}$ & BP $\downarrow ;$ bioavailability $\uparrow$ & & [213] \\
\hline \multicolumn{7}{|c|}{ Avoiding AS development } \\
\hline Lipid mixture & $60 \mathrm{~nm}$ & Docetaxel & $\begin{array}{l}\text { Rabbits; 8-week high- } \\
\text { cholesterol diet }\end{array}$ & $\begin{array}{l}\text { Atheroma area } \downarrow \text {; levels of } \\
\text { caspase } 3 \text {, caspase 9, Bax, Bcl-2, } \\
\text { MMP-2, MMP-9, TGF- } \beta, \text { NF-kB, } \\
\text { TNF- } \alpha \text {, IL-I } \beta, \text { IL-6, PCNA, vWF, } \\
\text { collagen I and } 3 \text { in the aortic } \\
\text { arch } \downarrow\end{array}$ & $\begin{array}{l}\text { No obvious } \\
\text { toxicity }\end{array}$ & [9] \\
\hline $\begin{array}{l}\text { Leukosomes } \\
\text { (liposome); } \\
\text { Fabricated with } \\
\text { membrane proteins } \\
\text { of macrophages }\end{array}$ & $108 \pm 2.3 \mathrm{~nm}$ & Rapamycin & $\begin{array}{l}\text { Mice; 12-week high-fat } \\
\text { diet }\end{array}$ & $\begin{array}{l}\text { Plaque burden } \downarrow \text {; proliferating } \\
\text { macrophages in the aorta } \downarrow \text {; } \\
\text { MCP-I, IL-bI, MMP } \downarrow\end{array}$ & $\begin{array}{l}\text { Good } \\
\text { tolerance }\end{array}$ & {$[90]$} \\
\hline PEGylated SWNTs & $5-6 \mathrm{~nm}$ & SHPIi & $\begin{array}{l}\text { ApoE-/- mice; } \\
\text { subcutaneous } \\
\text { angiotensin II-infusing } \\
\text { minipumps or II- } \\
\text { week high-fat diet }\end{array}$ & $\begin{array}{l}\text { Plaque burden } \downarrow \text {; lesional } \\
\text { phagocytosis } \uparrow \text {; inflammatory } \\
\text { genes in lesional macrophages } \downarrow\end{array}$ & $\begin{array}{l}\text { Favorable } \\
\text { safety profile }\end{array}$ & [177] \\
\hline rHDL & & TRAF-STOPs & ApoE-/- mice & $\begin{array}{l}\text { Atherosclerotic plaques } \downarrow \text {; } \\
\text { leukocyte recruitment } \downarrow \text {; } \\
\text { Macrophages activation } \downarrow\end{array}$ & $\begin{array}{l}\text { No } \\
\text { hepatotoxicity } \\
\text { or functional } \\
\text { hyposplenism }\end{array}$ & [178] \\
\hline
\end{tabular}


Table 4 (Continued).

\begin{tabular}{|c|c|c|c|c|c|c|}
\hline $\begin{array}{l}\text { Materials and } \\
\text { Modifications }\end{array}$ & $\begin{array}{l}\text { Particle } \\
\text { Size }\end{array}$ & Payload & Species and Model & $\begin{array}{l}\text { Therapeutic and Preventive } \\
\text { Effects }\end{array}$ & Safety & Ref. \\
\hline PEI & $\sim 45 \mathrm{~nm}$ & $\begin{array}{l}\text { ICAMI, } \\
\text { ICAM2, } \\
\text { VCAMI, Sel- } \\
\text { E, Sel-P } \\
\text { siRNAs }\end{array}$ & $\begin{array}{l}\text { ApoE-/- mice; high- } \\
\text { cholesterol diet and I/ } \\
R \text { injury (LAD for } \\
45 \mathrm{~min} \text { ) }\end{array}$ & $\begin{array}{l}\text { Neutrophil and monocyte } \\
\text { recruitment } \downarrow \text {, matrix-degrading } \\
\text { plaque protease activity } \downarrow\end{array}$ & & [187] \\
\hline PLGA & $\begin{array}{l}214.3 \pm 0.6 \mathrm{~nm} \\
(\mathrm{SRM}-\mathrm{NP}) \\
216.9 \pm 0.6 \mathrm{~nm} \\
(\mathrm{PTX}-\mathrm{NP})\end{array}$ & $\begin{array}{l}\text { Sirolimus } \\
\text { (SRM-NP) or } \\
\text { paclitaxel } \\
\text { (PTX-NP) }\end{array}$ & $\begin{array}{l}\text { Mini-pigs; temporary } \\
\text { carotid closure and } \\
\text { balloon angioplasty }\end{array}$ & $\begin{array}{l}\text { Vascular stenosis and } \\
\text { expression of PCNA } \downarrow \text {, } \\
\text { glycolysis and expression of } \\
\text { HIF-I } \alpha \text { in hypoxic ECs and } \\
\text { SMCs } \downarrow\end{array}$ & & {$[214]$} \\
\hline Lipid mixture & $53.9-95.9 \mathrm{~nm}$ & Curcumin & $\begin{array}{l}\text { Rats; temporary } \\
\text { carotid closure and } \\
\text { balloon angioplasty }\end{array}$ & Neointimal formation $\downarrow$; & & [215] \\
\hline $\begin{array}{l}\text { PLGA (SPN) or } \\
\text { liposome (LIP) }\end{array}$ & $\begin{array}{l}208 \pm 2 \mathrm{~nm} \\
(\mathrm{SPN}) ; \mathrm{I} 74 \\
\pm 2 \mathrm{~nm}(\mathrm{LIP})\end{array}$ & Methotrexate & $\begin{array}{l}\text { Mice; 28-day high-fat } \\
\text { diet }\end{array}$ & $\begin{array}{l}\text { Intracellular lipids and oxidized } \\
\text { LDL } \downarrow \text {; RANTES, IL-I } \beta \text {, TNF } \alpha \downarrow \text {; } \\
\text { IL-I } \alpha \uparrow\end{array}$ & & [216] \\
\hline $\begin{array}{l}\text { PEG and sebacic } \\
\text { acid }\end{array}$ & $\sim 100 \mathrm{~nm}$ & D-PDMP & $\begin{array}{l}\text { Mice; 8-week high-fat } \\
\text { and cholesterol diet }\end{array}$ & $\begin{array}{l}\text { AS plaque buildup, cholesterol } \\
\text { ester crystal deposits, and } \\
\text { fibrosis } \downarrow ; \text { FS } \uparrow \text { and cardiac } \\
\text { hypertrophy } \downarrow \\
\text { Oxidized LDL } \downarrow \text {; changes of } \\
\text { levels of genes associated with } \\
\text { triglyceride metabolism }\end{array}$ & & {$[217]$} \\
\hline Lipid NPs & $\begin{array}{l}45 \text { to } 60 \mathrm{~nm} \\
\text { (Ref. 219) }\end{array}$ & $\begin{array}{l}\text { Methotrexate } \\
\text { or paclitaxel }\end{array}$ & $\begin{array}{l}\text { Rabbits; high- } \\
\text { cholesterol diet (with } \\
\text { heterotopic heart } \\
\text { transplantation and } \\
\text { CsA administration in } \\
\text { Ref. } 218 \text { ) }\end{array}$ & $\begin{array}{l}\text { Coronary stenosis, } \\
\text { macrophages infiltration } \downarrow \text {; gene } \\
\text { expression of TNF } \alpha, \text { MCPI, IL- } \\
\text { I8, VCAMI, and MMPI } \downarrow \downarrow \text {; } \\
\text { expression of IL- } 10 \uparrow \text {; } \\
\text { Macroscopic atheroma plaque } \\
\text { area } \downarrow\end{array}$ & & {$[218,219]$} \\
\hline Lipid NPs & $60 \mathrm{~nm}$ & Carmustine & $\begin{array}{l}\text { Rabbits; 8-week } \\
\text { cholesterol diet }\end{array}$ & $\begin{array}{l}\text { Lesion areas } \downarrow \\
\text { Macrophages, FOXP3, IL-I } \beta \text {, } \\
\text { LDL-R } \downarrow\end{array}$ & & [220] \\
\hline \multicolumn{7}{|c|}{ Avoiding plaque rupture and thrombosis } \\
\hline $\begin{array}{l}\text { PEG/PEI (Loaded } \\
\text { into an E-selectin- } \\
\text { targeting multistage } \\
\text { microparticles) }\end{array}$ & & $\begin{array}{l}\operatorname{miR}-146 a \\
\operatorname{miR}-18 I b\end{array}$ & $\begin{array}{l}\text { ApoE-/- mice; I2- } \\
\text { week western diet }\end{array}$ & Plaque size $\downarrow$; Stabilization $\uparrow$ & & [126] \\
\hline $\begin{array}{l}\text { Perfluorocarbon } \\
\text { and excipient } \\
\text { combined with } \\
\text { alpha(nu)beta(3)- } \\
\text { integrin antagonist }\end{array}$ & & Fumagillin & $\begin{array}{l}\text { Hyperlipidemic } \\
\text { rabbits; 100-day } \\
\text { cholesterol diet }\end{array}$ & Acute antiangiogenic effects & & [182] \\
\hline
\end{tabular}

(Continued) 
Table 4 (Continued).

\begin{tabular}{|c|c|c|c|c|c|c|}
\hline $\begin{array}{l}\text { Materials and } \\
\text { Modifications }\end{array}$ & $\begin{array}{l}\text { Particle } \\
\text { Size }\end{array}$ & Payload & Species and Model & $\begin{array}{l}\text { Therapeutic and Preventive } \\
\text { Effects }\end{array}$ & Safety & Ref. \\
\hline $\begin{array}{l}\text { Albumin (linked to } \\
\text { microbubbles) }\end{array}$ & $\sim 225.6 \mathrm{~nm}$ & t-PA plasmid & $\begin{array}{l}\text { Dogs; coronary } \\
\text { bypass using the } \\
\text { autoallergic saphenous } \\
\text { vein }\end{array}$ & $\begin{array}{l}\text { Thrombotic rate } \downarrow \text {; Intimal } \\
\text { thickness and proliferation of } \\
\text { SMCs } \downarrow ; \text { t-PA and D-dimer } \\
\text { contents in blood } \uparrow\end{array}$ & & [183] \\
\hline $\begin{array}{l}\text { Amphipathic, } \\
\text { cationic peptide }\end{array}$ & $\sim 55 \mathrm{~nm}$ & JNK siRNA & $\begin{array}{l}\text { Mice; 14-week } \\
\text { western diet }\end{array}$ & $\begin{array}{l}\text { Barrier permeability and } \\
\text { disruption } \downarrow \text {; Foam cell } \\
\text { formation, plaque necrotic area } \\
\text { and Macrophages } \downarrow \text {; Thrombotic } \\
\text { risk } \downarrow \text {; NF- } \kappa B \text { and STAT3 } \\
\text { expression } \downarrow\end{array}$ & $\begin{array}{l}\text { No toxicity } \\
\text { in vivo }\end{array}$ & [184] \\
\hline $\begin{array}{l}\text { PEGylated and } \\
\text { cRGD-coated } \\
\text { liposomes }\end{array}$ & $\begin{array}{l}\mathrm{I} 64.6 \pm 5.3 \\
\mathrm{~nm}\end{array}$ & $t-P A$ & In vitro & Affinity $\uparrow ;$ Fibrin clot lysis $\uparrow$ & & [22I] \\
\hline
\end{tabular}

Abbreviations: SEM, scanning electron microscope; NOS, nitric oxide synthase activity; AGT, angiotensinogen; GSH, glutathione; LP(A), lipoprotein(A); PCNA, proliferating cell nuclear antigen; vWF, von Willebrand factor; SWNTs, single-walled carbon nanotubes; SHPIi, SH2 domain-containing phosphatase-I inhibitor; rHDL, recombinant high-density lipoprotein; TRAF-STOPs, tumor necrosis factor receptor associated factor (TRAF) 6; ICAM, intercellular cell adhesion molecule; VCAM, vascular cellular adhesion molecule; Sel, selectin; D-PDMP, D-Threo-I-phenyl-2-decanoylamino-3-morpholino-I-propanol; LDE, lipid nanoparticle; cRGD, cyclic arginine-glycineaspartic acid.

Primary prevention refers to control of the risk factors of AS, one of which is hypertension. ${ }^{170}$ PLA NPs have been shown to improve the efficacy of aliskiren, the first oral direct renin inhibitor and the first in a new class of antihypertensive agents. ${ }^{29}$ Encapsulation in nanocarriers also renders the application of anandamide viable, which was once limited; recent research revealed that this new therapy could lower blood pressure and LV mass index in rats. ${ }^{171}$ Similar results were observed in a study in which angiotensinogen was silenced using small hairpin RNA. ${ }^{172}$ NPs may also help to make more anti-hypertensive drugs available, reduce side effects such as asthma, and lessen the effective dosage by providing sustained drug release over time. The link between AS and diabetes mellitus, which describes a group of metabolic disorders, has also been investigated in numerous studies. ${ }^{173}$ Possible mechanisms include oxidative stress, altered protein kinase signaling, and epigenetic modifications. Cetin and colleagues successfully constructed NP-based drug delivery systems for the administration of metformin, an oral antihyperglycemic agent with low oral bioavailability and short biological half-life. ${ }^{174}$ NPs are also promising tools for improving the oral bioavailability of insulin, which is of great interest because oral insulin will significantly increase patients' compliance. ${ }^{175,176}$

The inflammatory hypothesis of AS is now widely established, making selective targeting and accumulation of NPs in inflammatory lesions attractive therapeutic strategies. Targeting macrophages in apoE-/- mice has been shown to result in decreased phagocytosis and suppression of inflammatory genes in lesional macrophages, thus lessening burden of atherosclerotic plaques. ${ }^{177}$ Tom and colleagues used NPs consisting of high-density lipoprotein (HDL), a known atheroprotective bionanomaterial, as carriers for TNF receptor-associated factor in mice, and observed reductions in both leukocyte recruitment and macrophage activation. ${ }^{178}$ Both single-walled CNT and HDL-NPs have a favorable safety profile. In a pathological context, activated endothelial tissue expresses more adhesion molecules, such as selectins, than usual. These molecules are thus potential targets for cardiovascular nanomedicine. Glycoprotein Ib (GPIb) ${ }^{179}$ and biotinylated Sialyl Lewis A (sLeA $)^{69}$ specifically bind to selectins, leading to the accumulation of conjugated NPs in injured vessels; an in vitro study demonstrated that GPIb-conjugated NPs could bind to target surfaces, where they were taken up by activated ECs under shear stress conditions. In another study, Sager and colleagues simultaneously inhibited five adhesion molecules associated with leukocyte recruitment in post-MI apoE-/- mice. Inflammation in plaque and ischemic heart, rendering acute coronary events and post-MI complications less likely to occur. ${ }^{180}$ However, targeting inflammatory process may have heterogeneous effects in humans 
because the targeting moieties and target receptors may be overexpressed in several different pathologic conditions in addition to AS. Oxidation is another factor involved in the development of AS. Upregulation of endothelial nitric oxide synthase (eNOS) leads to vascular construction and other AS-promoting effects. Pechanova and colleagues observed that the application of PLA NPs resulted in larger decreases in NOS than direct administration. ${ }^{29}$

Aside from these processes, avoiding plaque rupture and thrombosis could be another therapeutic aim. Nakashiro and colleagues showed that delivering pioglitazone via NPs inhibited plaque rupture in apoE-/- mice. ${ }^{181}$ The integrin $\alpha v \beta 3$ is upregulated in angiogenic vasculature, which is ubiquitous in plaque ruptures, which may lead to MI. ${ }^{182}$ $\alpha v \beta 3$ integrin-targeted NPs provide a site-specific drug delivery platform that has been shown to successfully stabilize plaques in rabbits. ${ }^{182} \mathrm{Ji}$ and colleagues used NPs composed of albumin with an average diameter of $225.6 \mathrm{~nm}$ to deliver a plasmid containing the tissue-type plasminogen activator gene (t-PA); this system plays a role in preventing thrombosis in addition to attenuating intimal thickness and proliferation of vascular SMCs. ${ }^{183}$ NPs consisting of engineered amphipathic cationic peptide and serine/threonine protein kinase JNK2 siRNA also reduces thrombotic risk, plaque necrotic area, and vascular barrier disorder in mice given the equivalent of a 14-week western diet. ${ }^{184}$

\section{The Future Prospects}

Innovation and development of therapies based on NPs in recent years has led to significant advances towards complete repair of the injured myocardium following acute MI. Nevertheless, developing clinically relevant solutions remains difficult for several reasons. Firstly, as shown in tables, there is little consistency among studies regarding the characteristics of NPs, their payloads, and their methods of administration, as well as methods used for evaluating cardiac repair. It can be difficult to control characteristics such as the size of the synthesized particles in a narrow range, even within single studies. Such significant heterogeneity can lead to differences in observed results in repeated experiments, or under different conditions. Secondly, although many studies have focused on the health effects of unintentional exposure to NPs by inhalation or ingestion, ${ }^{185,186}$ most of the studies on medical applications of NPs have not reported on toxicity of NP systems until recently. ${ }^{73}$ Remarkably, there has not been a consensus on NP-associated adverse effects in existing reports, making assessments of biocompatibility a priority for NP characterization.

NPs have emerged as a powerful tool for controlling cell signaling pathways in regenerative strategies using novel therapeutics and drugs that are unsuitable for direct administration. One advantage of the application of NP systems is the ability to release the drug payload or regulate gene expression in a stable and controlled manner. Therefore, many otherwise serious side effects, such as sudden arrhythmic deaths resulting from persistent and uncontrolled expression of miRNA by viral vectors, may be completely avoided. ${ }^{187}$ More research is required to develop stable and efficient methods of NP production, improve encapsulation efficiency of drugs, and achieve satisfactory targeting. In particular, a greater focus on investigating NP-based switches, including optical, electrical and magnetic methods, has enabled the regulation of cell signaling, exemplified by the development of a $\mathrm{CuS}$ NP-based photothermal switch. ${ }^{52}$ Optimizing tissue engineering scaffolds containing conductive NPs is a promising strategy for the protection of the myocardium after ischemia by mimicking the myocardial extracellular matrix. Improvements in understanding of cardiac repair mechanisms, and how these biomaterials may interfere with them, is therefore urgently needed. Furthermore, heart repair is complex and involves many processes, including apoptosis, angiogenesis, inflammatory infiltration, and fibrosis. Therefore, novel treatments should be designed using NPbased integrative strategies based on these multiple different mechanisms. However, it's important to highlight that synergistic effects of different drug payloads, NPs, and NP-cell combined strategies should be addressed, as not all may be compatible with one another. Future research should focus on these aspects to translate NP-based therapeutic strategies for MI into practical and effective clinical use.

\section{Disclosure}

The authors report no conflicts of interest in this work.

\section{References}

1. Reed GW, Rossi JE, Cannon CP. Acute myocardial infarction. Lancet. 2017;389(10065):197-210. doi:10.1016/s0140-6736(16)30677-8

2. Marín-Juez R, El-Sammak H, Helker CSM, et al. Coronary revascularization during heart regeneration is regulated by epicardial and endocardial cues and forms a scaffold for cardiomyocyte repopulation. Dev Cell. 2019;51(4):503-515.e4. doi:10.1016/j. devcel.2019.10.019

3. Rentrop KP, Feit F. Reperfusion therapy for acute myocardial infarction: concepts and controversies from inception to acceptance. Am Heart J. 2015;170(5):971-980. doi:10.1016/j.ahj.2015.08.005 
4. Arbab-Zadeh A, Nakano M, Virmani R, Fuster V. Acute coronary events. Circulation. 2012;125(9):1147-1156. doi:10.1161/ circulationaha.111.047431

5. Ou LC, Zhong S, Ou JS, Tian JW. Application of targeted therapy strategies with nanomedicine delivery for atherosclerosis. Acta Pharmacol Sin. 2021;42(1):10-17. doi:10.1038/s41401-0200436-0

6. Gorabi AM, Kiaie N, Reiner Ž, Carbone F, Montecucco F, Sahebkar A. The therapeutic potential of nanoparticles to reduce inflammation in atherosclerosis. Biomolecules. 2019;9(9):2545. doi:10.3390/biom9090416

7. Young DR, Hivert MF, Alhassan S, et al. Sedentary behavior and cardiovascular morbidity and mortality: a science advisory from the American Heart Association. Circulation. 2016;134(13): e262-79. doi:10.1161/cir.0000000000000440

8. Ekroos K, Jänis M, Tarasov K, Hurme R, Laaksonen R. Lipidomics: a tool for studies of atherosclerosis. Curr Atheroscler Rep. 2010;12(4):273-281. doi:10.1007/s11883-0100110-y

9. Meneghini BC, Tavares ER, Guido MC, et al. Lipid core nanoparticles as vehicle for docetaxel reduces atherosclerotic lesion, inflammation, cell death and proliferation in an atherosclerosis rabbit model. Vascul Pharmacol. 2019;115:46-54. doi:10.1016/j. vph.2019.02.003

10. Bulgarelli A, Martins Dias AA, Caramelli B, Maranhão RC. Treatment with methotrexate inhibits atherogenesis in cholesterol-fed rabbits. J Cardiovasc Pharmacol. 2012;59(4): 308-314. doi:10.1097/FJC.0b013e318241c385

11. Cervadoro A, Palomba R, Vergaro G, et al. Targeting inflammation with nanosized drug delivery platforms in cardiovascular diseases: immune cell modulation in atherosclerosis. Front Bioengineering Biotechnol. 2018;6:177. doi:10.3389/fbioe.20 18.00177

12. Zhang J, Zu Y, Dhanasekara CS, et al. Detection and treatment of atherosclerosis using nanoparticles. Wiley Interdiscip Rev Nanomed Nanobiotechnol. 2017;9(1). doi:10.1002/wnan.1412

13. Schmid P, Adams S, Rugo HS, et al. Atezolizumab and Nab-Paclitaxel in Advanced Triple-Negative Breast Cancer. $N$ Engl J Med. 2018;379(22):2108-2121. doi:10.1056/NEJMoa 1809615

14. Bahadur S, Sachan N, Harwansh RK, Deshmukh R. Nanoparticlized system: promising approach for the management of alzheimer's disease through intranasal delivery. Curr Pharm Des. 2020;26(12):1331-1344. doi:10.2174/13816128266662003 11131658

15. Wang W, Liu H, Lu Y, et al. Controlled-releasing hydrogen sulfide donor based on dual-modal iron oxide nanoparticles protects myocardial tissue from ischemia-reperfusion injury. Int J Nanomedicine. 2019;14:875-888. doi:10.2147/ijn.S186 225

16. Banik B, Surnar B, Askins BW, Banerjee M, Dhar S. Dualtargeted synthetic nanoparticles for cardiovascular diseases. ACS Appl Mater Interfaces. 2020;12(6):6852-6862. doi:10.1021/ acsami.9b19036

17. Yokoyama R, Ii M, Masuda M, et al. Cardiac regeneration by statin-polymer nanoparticle-loaded adipose-derived stem cell therapy in myocardial infarction. Stem Cells Transl Med. 2019;8 (10):1055-1067. doi:10.1002/sctm.18-0244

18. Wang J, Xiang B, Deng J, et al. Externally applied static magnetic field enhances cardiac retention and functional benefit of magnetically iron-labeled adipose-derived stem cells in infarcted hearts. Stem Cells Transl Med. 2016;5(10):1380-1393. doi:10.5966/ sctm.2015-0220

19. Gadde S, Rayner KJ. Nanomedicine Meets microRNA: current Advances in RNA-Based Nanotherapies for Atherosclerosis. ACS Nano. 2016;36(9):e73-9. doi:10.1161/atvbaha.116.307481
20. Sun Y, Lu Y, Yin L, Liu Z. The roles of nanoparticles in stem cell-based therapy for cardiovascular disease. Int J Nanomedicine. 2020;8:947. doi:10.3389/fbioe.2020.00947

21. Liu S, Chen X, Bao L, et al. Treatment of infarcted heart tissue via the capture and local delivery of circulating exosomes through antibody-conjugated magnetic nanoparticles. Nat Biomed Eng. 2020;4(11):1063-1075. doi:10.1038/s41551-020-00637-1

22. Pitek AS, Wang Y, Gulati S, et al. Elongated plant virus-based nanoparticles for enhanced delivery of thrombolytic therapies. $\mathrm{Mol}$ Pharm. 2017;14(11):3815-3823. doi:10.1021/acs.molpharmaceut. $7 \mathrm{~b} 00559$

23. Won YW, McGinn AN, Lee M, Bull DA, Kim SW. Targeted gene delivery to ischemic myocardium by homing peptide-guided polymeric carrier. Article. Mol Pharm. 2013;10(1):378-385. doi:10.1021/mp300500y

24. Sink E, Narayan SP, Abdel-Hafiz M, Mestroni L, Peña B. Nanomaterials for cardiac tissue engineering. Molecules. 2020; 25(21). doi:10.3390/molecules25215189

25. Zhang CX, Cheng Y, Liu DZ, et al. Mitochondria-targeted cyclosporin A delivery system to treat myocardial ischemia reperfusion injury of rats. J Nanobiotechnology. 2019;17(1):18. doi:10.1186/ s12951-019-0451-9

26. Oduk Y, Zhu W, Kannappan R, et al. VEGF nanoparticles repair the heart after myocardial infarction. Am J Physiol Heart Circ Physiol. 2018;314(2):H278-h284. doi:10.1152/ajpheart.00471. 2017

27. Caldas M, Santos AC, Veiga F, Rebelo R, Reis RL, Correlo VM. Melanin nanoparticles as a promising tool for biomedical applications - a review. Acta biomaterialia. 2020;105:26-43. doi:10.10 16/j.actbio.2020.01.044

28. Wang X, Wang C, Wang X, Wang Y, Zhang Q, Cheng Y. A polydopamine nanoparticle-knotted poly(ethylene glycol) hydrogel for on-demand drug delivery and chemo-photothermal therapy. Chem Mater. 2017;29(3):1370-1376. doi:10.1021/acs. chemmater.6b05192

29. Pechanova O, Barta A, Koneracka M, et al. Protective effects of nanoparticle-loaded aliskiren on cardiovascular system in spontaneously hypertensive rats. Molecules. 2019;24(15):2710. doi:10. 3390/molecules 24152710

30. Mao S, Wang L, Chen P, Lan Y, Guo R, Zhang M. Nanoparticlemediated delivery of Tanshinone IIA reduces adverse cardiac remodeling following myocardial infarctions in a mice model:

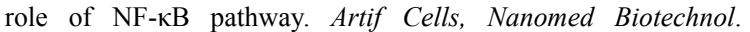
2018;46(sup3):S707-s716. doi:10.1080/21691401.2018.1508028

31. Guex AG, Kocher FM, Fortunato G, et al. Fine-tuning of substrate architecture and surface chemistry promotes muscle tissue development. Acta biomaterialia. 2012;8(4):1481-1489. doi:10. 1016/j.actbio.2011.12.033

32. Bae S, Park M, Kang C, et al. Hydrogen peroxide-responsive nanoparticle reduces myocardial ischemia/reperfusion injury. J Am Heart Assoc. 2016;5(11). doi:10.1161/jaha.116.003697

33. Wu S, Duan B, Qin X, Butcher JT. Living nano-micro fibrous woven fabric/hydrogel composite scaffolds for heart valve engineering. Acta biomaterialia. 2017;51:89-100. doi:10.1016/j. actbio.2017.01.051

34. Pok S, Vitale F, Eichmann SL, Benavides OM, Pasquali M, Jacot JG. Biocompatible carbon nanotube-chitosan scaffold matching the electrical conductivity of the heart. ACS Nano. 2014;8(10):9822-9832. doi:10.1021/nn503693h

35. Zhu K, Wu M, Lai H, et al. Nanoparticle-enhanced generation of gene-transfected mesenchymal stem cells for in vivo cardiac repair. Biomaterials. 2016;74:188-199. doi:10.1016/j.biomaterials.2015. 10.010

36. Singh B, Garg T, Goyal AK, Rath G. Recent advancements in the cardiovascular drug carriers. Artif Cells, Nanomed Biotechnol. 2016;44(1):216-225. doi:10.3109/21691401.2014.937868 
37. Jung H, Jang MK, Nah JW, Kim YB. Synthesis and Characterization of Thermosensitive Nanoparticles Based on PNIPAAm Core and Chitosan Shell Structure. Article. Macromol Res. 2009;17(4):265-270. doi:10.1007/bf03218690

38. Paliwal R, Paliwal SR, Kenwat R, Kurmi BD, Sahu MK. Solid lipid nanoparticles: a review on recent perspectives and patents. Expert Opin Ther Pat. 2020;30(3):179-194. doi:10.1080/1354 3776.2020.1720649

39. Piperigkou Z, Karamanou K, Engin AB, et al. Emerging aspects of nanotoxicology in health and disease: from agriculture and food sector to cancer therapeutics. Food Chem Toxicol. 2016;91:42-57. doi:10.1016/j.fct.2016.03.003

40. Chen W, Jarzyna PA, van Tilborg GA, et al. RGD peptide functionalized and reconstituted high-density lipoprotein nanoparticles as a versatile and multimodal tumor targeting molecular imaging probe. FASEB j. 2010;24(6):1689-1699. doi:10.1096/fj.09-139 865

41. Nguyen J, Sievers R, Motion JP, Kivimäe S, Fang Q, Lee RJ. Delivery of lipid micelles into infarcted myocardium using a lipid-linked matrix metalloproteinase targeting peptide. Mol Pharm. 2015;12(4):1150-1157. doi:10.1021/mp500653y

42. Ashtari K, Nazari H, Ko H, et al. Electrically conductive nanomaterials for cardiac tissue engineering. Adv Drug Deliv Rev. 2019;144:162-179. doi:10.1016/j.addr.2019.06.001

43. Kinnunen SM, Tölli M, Välimäki MJ, et al. Cardiac Actions of a Small Molecule Inhibitor Targeting GATA4-NKX2-5 Interaction. Sci Rep. 2018;8(1):4611. doi:10.1038/s41598-01822830-8

44. Dong Y, Hong M, Dai R, Wu H, Zhu P. Engineered bioactive nanoparticles incorporated biofunctionalized $\mathrm{ECM} /$ silk proteins based cardiac patches combined with MSCs for the repair of myocardial infarction: in vitro and in vivo evaluations. Sci Total Environ. 2020;707:135976. doi:10.1016/j.scitotenv.2019. 135976

45. Ramirez-Lee MA, Aguirre-Bañuelos P, Martinez-Cuevas PP, et al. Evaluation of cardiovascular responses to silver nanoparticles (AgNPs) in spontaneously hypertensive rats. Nanomedicine. 2018;14(2):385-395. doi:10.1016/j.nano.2017.11.013

46. Sharma AK, Kumar A, Sahu M, Sharma G, Datusalia AK, Rajput SK. Exercise preconditioning and low dose copper nanoparticles exhibits cardioprotection through targeting GSK- $3 \beta$ phosphorylation in ischemia/reperfusion induced myocardial infarction. Microvasc Res. 2018;120:59-66. doi:10.1016/j.mvr.20 18.06 .003

47. Zhang T, Dang M, Zhang W, Lin X. Gold nanoparticles synthesized from Euphorbia fischeriana root by green route method alleviates the isoprenaline hydrochloride induced myocardial infarction in rats. J Photochem Photobiol B. 2020;202:111705. doi:10.1016/j.jphotobiol.2019.111705

48. Tian A, Yang C, Zhu B, et al. Polyethylene-glycol-coated gold nanoparticles improve cardiac function after myocardial infarction in mice. Can J Physiol Pharmacol. 2018;96(12):1318-1327. doi:10.1139/cjpp-2018-0227

49. Hosoyama K, Ahumada M, Variola F, et al. Nanoengineered Electroconductive Collagen-Based Cardiac Patch for Infarcted Myocardium Repair. ACS Appl Mater Interfaces. 2018;10 (51):44668-44677. doi:10.1021/acsami.8b18844

50. You JO, Rafat M, Ye GJ, Auguste DT. Nanoengineering the heart: conductive scaffolds enhance connexin 43 expression. Nano Lett. 2011;11(9):3643-3648. doi:10.1021/n1201514a

51. Zhang BF, Jiang H, Chen J, Hu Q, Yang S, Liu XP. Silica-coated magnetic nanoparticles labeled endothelial progenitor cells alleviate ischemic myocardial injury and improve long-term cardiac function with magnetic field guidance in rats with myocardial infarction. J Cell Physiol. 2019;234(10):18544-18559. doi:10. $1002 /$ jcp. 28492
52. Gao W, Sun Y, Cai M, et al. Copper sulfide nanoparticles as a photothermal switch for TRPV1 signaling to attenuate atherosclerosis. Nat Commun. 2018;9(1):231. doi:10.1038/s414 67-017-02657-z

53. Liu N, Chen J, Zhuang J, Zhu P. Fabrication of engineered nanoparticles on biological macromolecular (PEGylated chitosan) composite for bio-active hydrogel system in cardiac repair applications. Int J Biol Macromol. 2018;117:553-558. doi:10. 1016/j.ijbiomac.2018.04.196

54. Zheng Y, Zhang H, Hu Y, Bai L, Xue J. MnO nanoparticles with potential application in magnetic resonance imaging and drug delivery for myocardial infarction. Int $J$ Nanomedicine. 2018;13:6177-6188. doi:10.2147/ijn.s176404

55. Xiong YY, Gong ZT, Tang RJ, Yang YJ. The pivotal roles of exosomes derived from endogenous immune cells and exogenous stem cells in myocardial repair after acute myocardial infarction. Theranostics. 2021;11(3):1046-1058. doi:10.7150/thno.53326

56. Huang P, Wang L, Li Q, et al. Atorvastatin enhances the therapeutic efficacy of mesenchymal stem cells-derived exosomes in acute myocardial infarction via up-regulating long non-coding RNA H19. Cardiovasc Res. 2020;116(2):353-367. doi:10.1093/ cvr/cvz139

57. Zhang LL, Xiong YY, Yang YJ. The vital roles of mesenchymal stem cells and the derived extracellular vesicles in promoting angiogenesis after acute myocardial infarction. Stem Cells Dev. 2021;30(11):561-577. doi:10.1089/scd.2021.0006

58. Rodrigo SF, van Ramshorst J, Hoogslag GE, et al. Intramyocardial injection of autologous bone marrow-derived ex vivo expanded mesenchymal stem cells in acute myocardial infarction patients is feasible and safe up to 5 years of follow-up. J Cardiovasc Transl Res. 2013;6(5):816-825. doi:10. 1007/s12265-013-9507-7

59. Wang Y, Zhang L, Li Y, et al. Exosomes/microvesicles from induced pluripotent stem cells deliver cardioprotective miRNAs and prevent cardiomyocyte apoptosis in the ischemic myocardium. Int $J$ Cardiol. 2015;192:61-69. doi:10.1016/j.ijcard.2015.05.020

60. Huang P, Tian X, Li Q, Yang Y. New strategies for improving stem cell therapy in ischemic heart disease. Heart Fail Rev. 2016;21(6):737-752. doi:10.1007/s10741-016-9576-1

61. Aillon KL, Xie Y, El-Gendy N, Berkland CJ, Forrest ML. Effects of nanomaterial physicochemical properties on in vivo toxicity. $A d v$ Drug Deliv Rev. 2009;61(6):457-466. doi:10.1016/j.addr.2009.03.010

62. Sun Y, Lu Y, Yin L, Liu Z. The roles of nanoparticles in stem cell-based therapy for cardiovascular disease. Front Bioengineering Biotechnol. 2020;8:947. doi:10.3389/fbioe.2020.00947

63. Chan CKW, Zhang L, Cheng CK, et al. Recent advances in managing atherosclerosis via nanomedicine. Small. 2018;14 (4):1702793. doi:10.1002/smll.201702793

64. Nahrendorf M, Jaffer FA, Kelly KA, et al. Noninvasive vascular cell adhesion molecule-1 imaging identifies inflammatory activation of cells in atherosclerosis. Circulation. 2006;114(14): 1504-1511. doi:10.1161/circulationaha.106.646380

65. Pérez-Medina $\mathrm{C}$, Binderup $\mathrm{T}$, Lobatto ME, et al. In Vivo PET Imaging of HDL in Multiple Atherosclerosis Models. JACC Cardiovasc Imaging. 2016;9(8):950-961. doi:10.1016/j.jcmg.20 16.01 .020

66. Champion JA, Mitragotri S. Role of target geometry in phagocytosis. Proc Natl Acad Sci U S A. 2006;103 (13):4930-4934. doi:10.1073/pnas.0600997103

67. Verma A, Stellacci F. Effect of surface properties on nanoparticle-cell interactions. Small. 2010;6(1):12-21. doi:10. 1002/smll.200901158

68. Yi S, Allen SD, Liu YG, et al. Tailoring nanostructure morphology for enhanced targeting of dendritic cells in atherosclerosis. ACS Nano. 2016;10(12):11290-11303. doi:10.1021/acsnano.6b 06451 
69. Palma-Chavez JA, Fuentes K, Applegate BE, Jo JA, Charoenphol P. Development and characterization of PLGA-based multistage delivery system for enhanced payload delivery to targeted vascular endothelium. Macromol Biosci. 2021;21(3):e2000377. doi:10.1002/mabi.202000377

70. Schöttler S, Becker G, Winzen S, et al. Protein adsorption is required for stealth effect of poly(ethylene glycol)- and poly(phosphoester)-coated nanocarriers. Nat Nanotechnol. 2016;11(4):372-377. doi:10.1038/nnano.2015.330

71. Zheng Y, Lu L, Yan Z, et al. mPEG-icariin nanoparticles for treating myocardial ischaemia. Artif Cells, Nanomed Biotechnol. 2019;47(1):801-811. doi:10.1080/21691401.2018.1554579

72. Mima Y, Abu Lila AS, Shimizu T, et al. Ganglioside inserted into PEGylated liposome attenuates anti-PEG immunity. J Controlled Release. 2017;250:20-26. doi:10.1016/j.jconrel.2017.01.040

73. Wang W, Chen J, Li M, et al. Rebuilding Postinfarcted Cardiac Functions by Injecting TIIA@PDA Nanoparticle-Cross-linked ROS-Sensitive Hydrogels. ACS Appl Mater Interfaces. 2019;11 (3):2880-2890. doi:10.1021/acsami.8b20158

74. Thomas TJ, Tajmir-Riahi HA, Pillai CKS. Biodegradable polymers for gene delivery. Molecules. 2019;24(20):3744. doi:10. 3390/molecules24203744

75. Yang X, Yang M, Pang B, Vara M, Xia Y. Gold nanomaterials at work in biomedicine. Chem Rev. 2015;115(19):10410-10488. doi:10.1021/acs.chemrev.5b00193

76. Saludas L, Pascual-Gil S, Roli F, Garbayo E, Blanco-Prieto MJ. Heart tissue repair and cardioprotection using drug delivery systems. Maturitas. 2018;110:1-9. doi:10.1016/j.maturitas.2018.01.011

77. Esfandyari-Manesh M, Abdi M, Talasaz AH, Ebrahimi SM, Atyabi F, Dinarvand R. S2P peptide-conjugated PLGA-Maleimide-PEG nanoparticles containing Imatinib for targeting drug delivery to atherosclerotic plaques. DARU J Pharmaceutical Sci. 2020;28(1):131-138. doi:10.1007/s40199019-00324-w

78. Cuadrado I, Piedras MJ, Herruzo I, et al. EMMPRIN-targeted magnetic nanoparticles for in vivo visualization and regression of acute myocardial infarction. Theranostics. 2016;6(4):545-557. doi: $10.7150 /$ thno. 13352

79. Ferreira MP, Ranjan S, Correia AM, et al. In vitro and in vivo assessment of heart-homing porous silicon nanoparticles. Biomaterials. 2016;94:93-104. doi:10.1016/j.biomaterials.2016.03.046

80. Boada C, Zinger A, Tsao C, et al. Rapamycin-loaded biomimetic nanoparticles reverse vascular inflammation. Circ Res. 2020;126 (1):25-37. doi:10.1161/circresaha.119.315185

81. Matoba T, Koga JI, Nakano K, Egashira K, Tsutsui $H$. Nanoparticle-mediated drug delivery system for atherosclerotic cardiovascular disease. J Cardiol. 2017;70(3):206-211. doi:10. 1016/j.jjcc.2017.03.005

82. Markovsky E, Baabur-Cohen H, Eldar-Boock A, et al. Administration, distribution, metabolism and elimination of polymer therapeutics. $J$ Control Release. 2012;161(2):446-460. doi:10.1016/j.jconrel.2011.12.021

83. Yao Y, Liao W, Yu R, Du Y, Zhang T, Peng Q. Potentials of combining nanomaterials and stem cell therapy in myocardial repair. Nanomedicine. 2018;13(13):1623-1638. doi:10.2217/ nnm-2018-0013

84. Bottini M, Bruckner S, Nika K, et al. Multi-walled carbon nanotubes induce T lymphocyte apoptosis. Toxicol Lett. 2006;160 (2):121-126. doi:10.1016/j.toxlet.2005.06.020

85. Hirano S, Kanno S, Furuyama A. Multi-walled carbon nanotubes injure the plasma membrane of macrophages. Toxicol Appl Pharmacol. 2008;232(2):244-251. doi:10.1016/j.taap.2008.06.016

86. Duan J, Yu Y, Yu Y, et al. Silica nanoparticles enhance autophagic activity, disturb endothelial cell homeostasis and impair angiogenesis. Part Fibre Toxicol. 2014;11:50. doi:10.1186/ s12989-014-0050-8
87. Duan J, Liang S, Yu Y, et al. Inflammation-coagulation response and thrombotic effects induced by silica nanoparticles in zebrafish embryos. Nanotoxicology. 2018;12(5):470-484. doi:10.1080/ 17435390.2018.1461267

88. Feng L, Yang X, Liang S, et al. Silica nanoparticles trigger the vascular endothelial dysfunction and prethrombotic state via miR-451 directly regulating the IL6R signaling pathway. Part Fibre Toxicol. 2019;16(1):16. doi:10.1186/s12989-019-0300-x

89. Gliga AR, Skoglund S, Wallinder IO, Fadeel B, Karlsson HL. Size-dependent cytotoxicity of silver nanoparticles in human lung cells: the role of cellular uptake, agglomeration and Ag release. Part Fibre Toxicol. 2014;11:11. doi:10.1186/1743-8977-11-11

90. Asharani PV, Lian Y, Gong Z, Valiyaveettil S. Toxicity of silver nanoparticles in zebrafish models. Nanotechnology. 2008;19 (25):255102. doi:10.1088/0957-4484/19/25/255102

91. Sereemaspun A, Rojanathanes R, Wiwanitkit V. Effect of gold nanoparticle on renal cell: an implication for exposure risk. Ren Fail. 2008;30(3):323-325. doi:10.1080/08860220701860914

92. Yang C, Tian A, Li Z. Reversible cardiac hypertrophy induced by PEG-coated gold nanoparticles in mice. Sci Rep. 2016;6:20203. doi:10.1038/srep20203

93. El-Hussainy HM, Hussein AM, Abdel-Aziz A, El-Mehasseb I. Effects of aluminum oxide (A12O3) nanoparticles on ECG, myocardial inflammatory cytokines, redox state, and connexin 43 and lipid profile in rats: possible cardioprotective effect of gallic acid. Can J Physiol Pharmacol. 2016;94(8):868-878. doi:10.1139/cjpp-2015-0446

94. Keyoumu Y, Huo Q, Cheng L, et al. The detailed biological investigations about combined effects of novel polyphenolic and photo-plasmonic nanoparticles loaded graphene nanosheets on coronary endothelial cells and isolated rat aortic rings. $J$ Photochem Photobiol B. 2020;202:111666. doi:10.1016/j.jphotobiol.2019.111666

95. Nemmar A, Beegam S, Yuvaraju P, et al. Ultrasmall superparamagnetic iron oxide nanoparticles acutely promote thrombosis and cardiac oxidative stress and DNA damage in mice. Part Fibre Toxicol. 2016;13(1):22. doi:10.1186/s12989-016-0132-x

96. Babiker F, Benter IF, Akhtar S. Nanotoxicology of Dendrimers in the Mammalian Heart: ex vivo and in vivo Administration of G6 PAMAM Nanoparticles Impairs Recovery of Cardiac Function Following Ischemia-Reperfusion Injury. Int $J$ Nanomedicine. 2020;15:4393-4405. doi:10.2147/ijn.s255202

97. Gao L, Gregorich ZR, Zhu W, et al. Large cardiac muscle patches engineered from human induced-pluripotent stem cell-derived cardiac cells improve recovery from myocardial infarction in swine. Circulation. 2018;137(16):1712-1730. doi:10.1161/ circulationaha.117.030785

98. Goodman CM, McCusker CD, Yilmaz T, Rotello VM. Toxicity of gold nanoparticles functionalized with cationic and anionic side chains. Bioconjug Chem. 2004;15(4):897-900. doi:10.1021/bc 049951i

99. Shin SR, Jung SM, Zalabany M, et al. Carbon-nanotubeembedded hydrogel sheets for engineering cardiac constructs and bioactuators. ACS Nano. 2013;7(3):2369-2380. doi:10.1021/ $\mathrm{nn} 305559 \mathrm{j}$

100. Costa PM, Bourgognon M, Wang JT, Al-Jamal KT. Functionalised carbon nanotubes: from intracellular uptake and cell-related toxicity to systemic brain delivery. $J$ Controlled Release. 2016;241:200-219. doi:10.1016/j.jconrel.2016.09.033

101. Ikeda G, Matoba T, Nakano Y, et al. Nanoparticle-mediated targeting of cyclosporine a enhances cardioprotection against ischemia-reperfusion injury through inhibition of mitochondrial permeability transition pore opening. Sci Rep. 2016;6:20467. doi:10.1038/srep20467

102. Maranhão RC, Guido $\mathrm{MC}$, de Lima $\mathrm{AD}$, et al. Methotrexate carried in lipid core nanoparticles reduces myocardial infarction size and improves cardiac function in rats. Int $J$ Nanomedicine. 2017;12:3767-3784. doi:10.2147/ijn.S129324 
103. Margulis K, Neofytou EA, Beygui RE, Zare RN. Celecoxib Nanoparticles for Therapeutic Angiogenesis. ACS Nano. 2015;9 (9):9416-9426. doi:10.1021/acsnano.5b04137

104. Tokutome M, Matoba T, Nakano Y, et al. Peroxisome proliferator-activated receptor-gamma targeting nanomedicine promotes cardiac healing after acute myocardial infarction by skewing monocyte/macrophage polarization in preclinical animal models. Cardiovasc Res. 2019;115(2):419-431. doi:10.1093/cvr/ cvy200

105. Qi Q, Lu L, Li H, et al. Spatiotemporal delivery of nanoformulated liraglutide for cardiac regeneration after myocardial infarction. Int J Nanomedicine. 2017;12:4835-4848. doi:10.2147/ijn.s132064

106. Zhang Y, Qian P, Zhou H, et al. Pharmacological signatures of the exenatide nanoparticles complex against myocardial ischemia reperfusion injury. Kidney Blood Press Res. 2018;43 (4):1273-1284. doi:10.1159/000492409

107. Ichimura K, Matoba T, Nakano K, et al. A translational study of a new therapeutic approach for acute myocardial infarction: nanoparticle-mediated delivery of pitavastatin into reperfused myocardium reduces ischemia-reperfusion injury in a preclinical porcine model. PLoS One. 2016;11(9):e0162425. doi:10.1371/ journal.pone. 0162425

108. Cheng Y, Liu DZ, Zhang CX, et al. Mitochondria-targeted antioxidant delivery for precise treatment of myocardial ischemia-reperfusion injury through a multistage continuous targeted strategy. Nanomedicine. 2019;16:236-249. doi:10.1016/j. nano.2018.12.014

109. Dong Z, Guo J, Xing X, Zhang X, Du Y, Lu Q. RGD modified and PEGylated lipid nanoparticles loaded with puerarin: formulation, characterization and protective effects on acute myocardial ischemia model. Biomed Pharmacother. 2017;89:297-304. doi:10.1016/j.biopha.2017.02.029

110. Liu CJ, Yao L, Hu YM, Zhao BT. Effect of quercetin-loaded mesoporous silica nanoparticles on myocardial ischemia-reperfusion injury in rats and its mechanism. Int J Nanomedicine. 2021;16:741-752. doi:10.2147/ijn.s277377

111. Boarescu PM, Chirilă I, Bulboacă AE, et al. Effects of curcumin nanoparticles in isoproterenol-induced myocardial infarction. Oxid Med Cell Longev. 2019;2019:7847142. doi:10.1155/2019/7847142

112. Fujiwara M, Matoba T, Koga JI, et al. Nanoparticle incorporating Toll-like receptor 4 inhibitor attenuates myocardial ischaemia-reperfusion injury by inhibiting monocyte-mediated inflammation in mice. Cardiovasc Res. 2019;115(7):1244-1255. doi:10.1093/cvr/cvz066

113. Ferreira MPA, Ranjan S, Kinnunen S, et al. Drug-loaded multifunctional nanoparticles targeted to the endocardial layer of the injured heart modulate hypertrophic signaling. Small. 2017;13 (33):548. doi:10.1002/smll.201701276

114. Qiao B, Nie JJ. Functional nanocomplexes with vascular endothelial growth factor $\mathrm{a} / \mathrm{c}$ isoforms improve collateral circulation and cardiac function. Small. 2020;16(4):e1905925. doi:10.1002/smll.201905925

115. Ding Y, Zhao AS, Liu T, et al. An Injectable Nanocomposite Hydrogel for Potential Application of Vascularization and Tissue Repair. Ann Biomed Eng. 2020;48(5):1511-1523. doi:10.1007/ s10439-020-02471-7

116. Garbayo E, Pascual-Gil S. Nanomedicine and drug delivery systems in cancer and regenerative medicine. Wiley Interdiscip Rev Nanomed Nanobiotechnol. 2020;12(5):e1637. doi:10.1002/wnan.1637

117. Fang R, Qiao S, Liu Y, et al. Sustained co-delivery of BIO and IGF-1 by a novel hybrid hydrogel system to stimulate endogenous cardiac repair in myocardial infarcted rat hearts. Int J Nanomedicine. 2015;10:4691-4703. doi:10.2147/ijn.s81451

118. Awada HK, Long DW, Wang Z, Hwang MP, Kim K, Wang Y. A single injection of protein-loaded coacervate-gel significantly improves cardiac function post infarction. Biomaterials. 2017;125:65-80. doi:10.1016/j.biomaterials.2017.02.020
119. Somasuntharam I, Yehl K, Carroll SL, et al. Knockdown of TNF$\alpha$ by DNAzyme gold nanoparticles as an anti-inflammatory therapy for myocardial infarction. Biomaterials. 2016;83:12-22. doi:10.1016/j.biomaterials.2015.12.022

120. Kataria K, Sharma A, Garg T, K. goyal A, Rath G. Novel technology to improve drug loading in polymeric nanofibers. Drug Deliv Lett. 2014;4(1):79-86. doi:10.2174/22103031113036660018

121. Kim HJ, Oh HJ, Park JS, Lee JS, Kim JH, Park KH. Direct conversion of human dermal fibroblasts into cardiomyocyte-like cells using CiCMC Nanogels Coupled with Cardiac Transcription Factors and a Nucleoside Drug. Advanced Science (Weinheim, Baden-Wurttemberg, Germany). 2020;7(7):1901818. doi:10.10 02/advs. 201901818

122. Turnbull IC, Eltoukhy AA, Fish KM, et al. Myocardial delivery of lipidoid nanoparticle carrying modrna induces rapid and transient expression. Mol Therapy. 2016;24(1):66-75. doi:10.1038/ mt.2015.193

123. Nie JJ, Qiao B, Duan S, et al. Unlockable nanocomplexes with self-accelerating nucleic acid release for effective staged gene therapy of cardiovascular diseases. Adv Materials. 2018;30(31): e1801570. doi:10.1002/adma.201801570

124. Bejerano T, Etzion S, Elyagon S, Etzion Y, Cohen S. Nanoparticle Delivery of miRNA-21 Mimic to Cardiac Macrophages Improves Myocardial Remodeling after Myocardial Infarction. Nano Lett. 2018;18(9):5885-5891. doi:10.1021/acs.nanolett.8b02578

125. Mirna M, Paar V, Topf A, et al. A new player in the game: treatment with antagomiR-21a-5p significantly attenuates histological and echocardiographic effects of experimental autoimmune myocarditis. Cardiovasc Res. 2021. doi:10.1093/cvr/cvab015

126. Yang $\mathrm{H}$, Qin $\mathrm{X}$, Wang $\mathrm{H}$, et al. An in Vivo miRNA Delivery System for Restoring Infarcted Myocardium. ACS Nano. 2019;13 (9):9880-9894. doi:10.1021/acsnano.9b03343

127. Ma S, Tian XY, Zhang Y, et al. E-selectin-targeting delivery of microRNAs by microparticles ameliorates endothelial inflammation and atherosclerosis. Sci Rep. 2016;6:22910. doi:10.1038/ srep22910

128. Sayed N, Tambe P, Kumar P, Jadhav S, Paknikar KM, Gajbhiye V. miRNA transfection via poly(amidoamine)-based delivery vector prevents hypoxia/reperfusion-induced cardiomyocyte apoptosis. Nanomedicine. 2020;15(2):163-181. doi:10.2217/ nnm-2019-0363

129. Xue X, Shi X, Dong H, et al. Delivery of microRNA-1 inhibitor by dendrimer-based nanovector: an early targeting therapy for myocardial infarction in mice. Nanomedicine. 2018;14 (2):619-631. doi:10.1016/j.nano.2017.12.004

130. Dosta P, Demos C, Ramos V, et al. Delivery of siRNA to Endothelial Cells In Vivo Using Lysine/Histidine OligopeptideModified Poly( $\beta$-amino ester) Nanoparticles. Cardiovasc Eng Technol. 2021;12(1):114-125. doi:10.1007/s13239-02100518-x

131. Lu W, Xie Z, Tang Y, et al. Photoluminescent mesoporous silicon nanoparticles with siCCR2 improve the effects of mesenchymal stromal cell transplantation after acute myocardial infarction. Theranostics. 2015;5(10):1068-1082. doi:10.7150/thno.11517

132. Izadifar M, Chapman D, Babyn P, Chen X. UV-Assisted 3d bioprinting of nanoreinforced hybrid cardiac patch for myocardial tissue engineering. Tissue Eng Part C Methods. 2018;24(2): 74-88. doi:10.1089/ten.TEC.2017.0346

133. Ho CM, Mishra A, Lin PT, et al. 3D Printed polycaprolactone carbon nanotube composite scaffolds for cardiac tissue engineering. Macromol Biosci. 2017;17(4):1600250. doi:10.10 02/mabi.201600250

134. Kharaziha M, Shin SR, Nikkhah M, et al. Tough and flexible CNT-polymeric hybrid scaffolds for engineering cardiac constructs. Biomaterials. 2014;35(26):7346-7354. doi:10.1016/j. biomaterials.2014.05.014 
135. Navaei A, Saini H, Christenson W, Sullivan RT, Ros R, Nikkhah M. Gold nanorod-incorporated gelatin-based conductive hydrogels for engineering cardiac tissue constructs. Acta biomaterialia. 2016;41:133-146. doi:10.1016/j.actbio.2016.05.027

136. Ahadian S, Davenport Huyer L, Estili M, et al. Moldable elastomeric polyester-carbon nanotube scaffolds for cardiac tissue engineering. Acta biomaterialia. 2017;52:81-91. doi:10.1016/j. actbio.2016.12.009

137. Zhou J, Chen J, Sun H, et al. Engineering the heart: evaluation of conductive nanomaterials for improving implant integration and cardiac function. Sci Rep. 2014;4:3733. doi:10.1038/srep03733

138. Baei P, Jalili-Firoozinezhad S, Rajabi-Zeleti S, TafazzoliShadpour M, Baharvand H, Aghdami N. Electrically conductive gold nanoparticle-chitosan thermosensitive hydrogels for cardiac tissue engineering. Mater Sci Eng C Mater Biol Appl. 2016;63:131-141. doi:10.1016/j.msec.2016.02.056

139. Navaei A, Rahmani Eliato K, Ros R, Migrino RQ, Willis BC, Nikkhah $M$. The influence of electrically conductive and non-conductive nanocomposite scaffolds on the maturation and excitability of engineered cardiac tissues. Biomaterials sci. 2019;7(2):585-595. doi:10.1039/c8bm01050a

140. Martinelli V, Cellot G, Toma FM, et al. Carbon nanotubes promote growth and spontaneous electrical activity in cultured cardiac myocytes. Nano Lett. 2012;12(4):1831-1838. doi:10.1021/nl204064s

141. Peña B, Maldonado M, Bonham AJ, et al. Gold Nanoparticle-Functionalized Reverse Thermal Gel for Tissue Engineering Applications. ACS Appl Mater Interfaces. 2019;11 (20):18671-18680. doi:10.1021/acsami.9b00666

142. Mombini S, Mohammadnejad J, Bakhshandeh B, et al. ChitosanPVA-CNT nanofibers as electrically conductive scaffolds for cardiovascular tissue engineering. Int $J$ Biol Macromol. 2019;140:278-287. doi:10.1016/j.ijbiomac.2019.08.046

143. Thrivikraman G, Madras G, Basu B. Electrically driven intracellular and extracellular nanomanipulators evoke neurogenic/cardiomyogenic differentiation in human mesenchymal stem cells. Biomaterials. 2016;77:26-43. doi:10.1016/j.biomaterials.2015. 10.078

144. Li Y, Shi X, Tian L, et al. AuNP-collagen matrix with localized stiffness for cardiac-tissue engineering: enhancing the assembly of intercalated discs by $\beta 1$-integrin-mediated signaling. Adv Materials. 2016;28(46):10230-10235. doi:10.1002/adma.201603027

145. Allison S, Ahumada M, Andronic C, et al. Electroconductive nanoengineered biomimetic hybrid fibers for cardiac tissue engineering. $J$ Materials Chem B. 2017;5(13):2402-2406. doi:10.1039/c7tb00405b

146. Xu JY, Xiong YY, Lu XT, Yang YJ. Regulation of Type 2 Immunity in Myocardial Infarction. Front Immunol. 2019;10:62. doi:10.3389/fimmu.2019.00062

147. Li X, Zhou J, Liu Z, et al. A PNIPAAm-based thermosensitive hydrogel containing SWCNTs for stem cell transplantation in myocardial repair. Biomaterials. 2014;35(22):5679-5688. doi:10. 1016/j.biomaterials.2014.03.067

148. Kalishwaralal K, Jeyabharathi S, Sundar K, Selvamani S, Prasanna M, Muthukumaran A. A novel biocompatible chitosan-Selenium nanoparticles (SeNPs) film with electrical conductivity for cardiac tissue engineering application. Mater Sci Eng C Mater Biol Appl. 2018;92:151-160. doi:10.1016/j.msec.2018.06.036

149. Nazari H, Heirani-Tabasi A, Hajiabbas M, et al. Incorporation of SPION-casein core-shells into silk-fibroin nanofibers for cardiac tissue engineering. J Cell Biochem. 2020;121(4):2981-2993. doi:10.1002/jcb.29553

150. Mou Y, Lv S, Xiong F, et al. Effects of different doses of 2,3-dimercaptosuccinic acid-modified $\mathrm{Fe}(2) \mathrm{O}(3)$ nanoparticles on intercalated discs in engineered cardiac tissues. $J$ Biomed Mater Res B Appl Biomater. 2018;106(1):121-130. doi:10.1002/ jbm.b.33757
151. Chouhan D, Mehrotra S, Majumder O. Magnetic actuator device assisted modulation of cellular behavior and tuning of drug release on silk platform. ACS Biomater Sci Eng. 2019;5:92-105. doi:10.1021/acsbiomaterials. 8 b00240

152. Zwi-Dantsis L, Wang B, Marijon C, et al. Remote magnetic nanoparticle manipulation enables the dynamic patterning of cardiac tissues. Adv Materials. 2020;32(6):e1904598. doi:10.1002/ adma.201904598

153. McClements DJ. Designing biopolymer microgels to encapsulate, protect and deliver bioactive components: physicochemical aspects. Adv Colloid Interface Sci. 2017;240:31-59. doi:10.10 16/j.cis.2016.12.005

154. Wang L, Jiang J, Hua W. Mussel-inspired conductive cryogel as cardiac tissue patch to repair myocardial infarction by migration of conductive nanoparticles. Adv Funct Mater. 2016;26: 4293-4305. doi:10.1002/adfm.201505372

155. He Y, Ye G, Song C, et al. Mussel-inspired conductive nanofibrous membranes repair myocardial infarction by enhancing cardiac function and revascularization. Theranostics. 2018;8 (18):5159-5177. doi:10.7150/thno.27760

156. Orlic D, Kajstura J, Chimenti S, et al. Bone marrow cells regenerate infarcted myocardium. Nature. 2001;410(6829):701-705. doi: $10.1038 / 35070587$

157. Xu J, Xiong YY, Li Q, et al. Optimization of timing and times for administration of atorvastatin-pretreated mesenchymal stem cells in a preclinical model of acute myocardial infarction. Stem Cells Transl Med. 2019;8(10):1068-1083. doi:10.1002/sctm.19-0013

158. Chistiakov DA, Melnichenko AA, Orekhov AN, Bobryshev YV. Engineered nanoparticles: their properties and putative applications for therapeutic approaches utilizing stem cells for the repair of atherosclerotic disease. Nat Biomed Eng. 2018;19 (14):1639-1648. doi:10.2174/1389450118666171027111528

159. Vandergriff AC, Hensley TM, Henry ET, et al. Magnetic targeting of cardiosphere-derived stem cells with ferumoxytol nanoparticles for treating rats with myocardial infarction. Biomaterials. 2014;35(30):8528-8539. doi:10.1016/j.biomaterials.2014.06.031

160. Cheng K, Shen D, Hensley MT, et al. Magnetic antibody-linked nanomatchmakers for therapeutic cell targeting. Nat Commun. 2014;5:4880. doi:10.1038/ncomms5880

161. Chen F, Zhao ER, Hableel G, et al. Increasing the Efficacy of Stem Cell Therapy via Triple-Function Inorganic Nanoparticles. ACS Nano. 2019;13(6):6605-6617. doi:10.1021/acsnano.9b00653

162. Wang J, Xiang B, Deng JX, et al. Hypoxia enhances the therapeutic potential of superparamagnetic iron oxide-labeled adipose-derived stem cells for myocardial infarction. J Huazhong Univ Sci Technol Med Sci. 2017;37(4):516-522. doi:10.1007/s11596-017-1766-0

163. Li H, Liao Y, Gao L, et al. Coronary serum exosomes derived from patients with myocardial ischemia regulate angiogenesis through the mir-939-mediated nitric oxide signaling pathway. Theranostics. 2018;8(8):2079-2093. doi:10.7150/thno.21895

164. Cheng M, Yang J, Zhao X, et al. Circulating myocardial microRNAs from infarcted hearts are carried in exosomes and mobilise bone marrow progenitor cells. Nat Commun. 2019;10 (1):959. doi:10.1038/s41467-019-08895-7

165. Chen GH, Xu J, Yang YJ. Exosomes: promising sacks for treating ischemic heart disease? Am J Physiol Heart Circ Physiol. 2017;313(3):H508-h523. doi:10.1152/ajpheart.00213.2017

166. Xu JY, Chen GH, Yang YJ. Exosomes: a rising star in falling hearts. Front Physiol. 2017;8:494. doi:10.3389/fphys.2017.00494

167. Tan SJO, Floriano JF, Nicastro L, Emanueli C, Catapano F. Novel applications of mesenchymal stem cell-derived exosomes for myocardial infarction therapeutics. Biomolecules. 2020;10(5). doi:10.3390/biom 10050707

168. Libby P. Inflammation in atherosclerosis. Arterioscler Thromb Vasc Biol. 2012;32(9):2045-2051. doi:10.1161/atvbaha.108.17 9705 
169. Allen S, Liu YG, Scott E. Engineering nanomaterials to address cell-mediated inflammation in atherosclerosis. Regenerative Eng Translational Med. 2016;2(1):37-50. doi:10.1007/s40883-0160012-9

170. Ning B, Chen Y, Waqar AB, et al. Hypertension enhances advanced atherosclerosis and induces cardiac death in Watanabe heritable hyperlipidemic rabbits. Am J Pathol. 2018;188 (12):2936-2947. doi:10.1016/j.ajpath.2018.08.007

171. Martín Giménez VM, Díaz-Rodríguez P, Sanz RL, et al. Anandamide-nanoformulation obtained by electrospraying for cardiovascular therapy. Int $J$ Pharm. 2019;566:1-10. doi:10.1016/j.ijpharm.2019.05.047

172. Yuan LF, Sheng J, Lu P, Wang YQ, Jin T, Du Q. Nanoparticlemediated RNA interference of angiotensinogen decreases blood pressure and improves myocardial remodeling in spontaneously hypertensive rats. Mol Med Rep. 2015;12(3):4657-4663. doi:10.3892/mmr.2015.3909

173. Poznyak A, Grechko AV, Poggio P, Myasoedova VA, Alfieri V, Orekhov AN. The diabetes mellitus-atherosclerosis connection: the role of lipid and glucose metabolism and chronic inflammation. Int J Mol Sci. 2020;21(5):1835. doi:10.3390/ijms21051835

174. Cetin M, Sahin S. Microparticulate and nanoparticulate drug delivery systems for metformin hydrochloride. Drug Deliv. 2016;23(8):2796-2805. doi:10.3109/10717544.2015.1089957

175. Li P, Nielsen HM, Fano M, Müllertz A. Preparation and characterization of insulin-surfactant complexes for loading into lipid-based drug delivery systems. J Pharm Sci. 2013;102 (8):2689-2698. doi:10.1002/jps.23640

176. Ahn S, Lee IH, Lee E, Kim H, Kim YC, Jon S. Oral delivery of an anti-diabetic peptide drug via conjugation and complexation with low molecular weight chitosan. J Controlled Release. 2013;170(2):226-232. doi:10.1016/j.jconrel.2013.05.031

177. Flores AM, Hosseini-Nassab N, Jarr KU, et al. Pro-efferocytic nanoparticles are specifically taken up by lesional macrophages and prevent atherosclerosis. Nat Nanotechnol. 2020;15 (2):154-161. doi:10.1038/s41565-019-0619-3

178. Seijkens TTP, van Tiel CM, Kusters PJH, et al. Targeting CD40-Induced TRAF6 Signaling in Macrophages Reduces Atherosclerosis. J Am Coll Cardiol. 2018;71(5):527-542. doi:10. 1016/j.jacc.2017.11.055

179. Kona S, Dong JF, Liu Y, Tan J, Nguyen KT. Biodegradable nanoparticles mimicking platelet binding as a targeted and controlled drug delivery system. Int J Pharm. 2012;423(2):516-524. doi:10.1016/j.ijpharm.2011.11.043

180. Sager HB, Dutta P, Dahlman JE, et al. RNAi targeting multiple cell adhesion molecules reduces immune cell recruitment and vascular inflammation after myocardial infarction. Sci Transl Med. 2016;8(342):342ra80. doi:10.1126/scitranslmed.aaf1435

181. Nakashiro S, Matoba T, Umezu R, et al. PioglitazoneIncorporated Nanoparticles Prevent Plaque Destabilization and Rupture by Regulating Monocyte/Macrophage Differentiation in ApoE-/- Mice. Arterioscler Thromb Vasc Biol. 2016;36(3): 491-500. doi:10.1161/atvbaha.115.307057

182. Winter PM, Caruthers SD, Zhang H, Williams TA, Wickline SA, Lanza GM. Antiangiogenic synergism of integrin-targeted fumagillin nanoparticles and atorvastatin in atherosclerosis. JACC Cardiovasc Imaging. 2008;1(5):624-634. doi:10.1016/j.jcmg.2008.06.003

183. Ji J, Yang JA, He X, Ling WP, Chen XL. Cardiac-targeting transfection of tissue-type plasminogen activator gene to prevent the graft thrombosis and vascular anastomotic restenosis after coronary bypass. Thromb Res. 2014;134(2):440-448. doi:10. 1016/j.thromres.2014.04.018

184. Pan H, Palekar RU, Hou KK, et al. Anti-JNK2 peptide-siRNA nanostructures improve plaque endothelium and reduce thrombotic risk in atherosclerotic mice. Int $J$ Nanomedicine. 2018; 13:5187-5205. doi:10.2147/ijn.S168556
185. Ferdous Z, Al-Salam S, Greish YE, Ali BH, Nemmar A. Pulmonary exposure to silver nanoparticles impairs cardiovascular homeostasis: effects of coating, dose and time. Toxicol Appl Pharmacol. 2019;367:36-50. doi:10.1016/j.taap.2019.01.006

186. Rossi S, Savi M, Mazzola M, et al. Subchronic exposure to titanium dioxide nanoparticles modifies cardiac structure and performance in spontaneously hypertensive rats. Particle Fibre Toxicol. 2019;16(1):25. doi:10.1186/s12989-019-0311-7

187. Nakano Y, Matoba T, Tokutome M, et al. Nanoparticle-mediated delivery of irbesartan induces cardioprotection from myocardial ischemia-reperfusion injury by antagonizing monocyte-mediated inflammation. Sci Rep. 2016;6:29601. doi:10.1038/srep29601

188. Tong F, Liu S, Yan B, Li X, Ruan S, Yang S. Endogenous ornithine decarboxylase/polyamine system mediated the antagonist role of insulin/PEG-CMCS preconditioning against heart ischemia/reperfusion injury in diabetes mellitus. Int $J$ Nanomedicine. 2018;13:2507-2520. doi:10.2147/ijn.s160848

189. Huang Z, Song Y, Pang Z, et al. Targeted delivery of thymosin beta 4 to the injured myocardium using CREKA-conjugated nanoparticles. Int $J$ Nanomedicine. 2017;12:3023-3036. doi:10.2147/ijn.S131949

190. Bei W, Jing L, Chen N. Cardio protective role of wogonin loaded nanoparticle against isoproterenol induced myocardial infarction by moderating oxidative stress and inflammation. Colloids Surf $B$ Biointerfaces. 2020;185:110635. doi:10.1016/j.colsurfb.20 19.110635

191. Zhang S, Wang J, Pan J. Baicalin-loaded PEGylated lipid nanoparticles: characterization, pharmacokinetics, and protective effects on acute myocardial ischemia in rats. Drug Deliv. 2016;23(9):3696-3703. doi:10.2147/ijn.s131893

192. Qiu J, Cai G, Liu X, Ma D. $\alpha(v) \beta(3)$ integrin receptor specific peptide modified, salvianolic acid $\mathrm{B}$ and panax notoginsenoside loaded nanomedicine for the combination therapy of acute myocardial ischemia. Biomed Pharmacother. 2017;96:1418-1426. doi:10.1016/j.biopha.2017.10.086

193. Shao M, Yang W, Han G. Protective effects on myocardial infarction model: delivery of schisandrin B using matrix metalloproteinase-sensitive peptide-modified, PEGylated lipid nanoparticles. Int J Nanomedicine. 2017;12:7121-7130. doi:10. 2147/ijn.S141549

194. Tan ME, He CH, Jiang W, et al. Development of solid lipid nanoparticles containing total flavonoid extract from Dracocephalum moldavica L. and their therapeutic effect against myocardial ischemia-reperfusion injury in rats. Int $J$ Nanomedicine. 2017;12:3253-3265. doi:10.2147/ijn.s13 1893

195. Vinodhini A, Govindaraju K, Singaravelu G, Sadiq AM, Kumar VG. Cardioprotective potential of biobased gold nanoparticles. Colloids Surf B Biointerfaces. 2014;117:480-486. doi:10.1016/j.colsurfb.2014.01.006

196. Mihalko E, Huang K, Sproul E, Cheng K, Brown AC. Targeted Treatment of Ischemic and Fibrotic Complications of Myocardial Infarction Using a Dual-Delivery Microgel Therapeutic. ACS Nano. 2018;12(8):7826-7837. doi:10.1021/acsnano.8b01977

197. Ishikita A, Matoba T, Ikeda G, et al. Nanoparticle-Mediated Delivery of Mitochondrial Division Inhibitor 1 to the Myocardium Protects the Heart From Ischemia-Reperfusion Injury Through Inhibition of Mitochondria Outer Membrane Permeabilization: a New Therapeutic Modality for Acute Myocardial Infarction. J Am Heart Assoc. 2016;5(7). doi:10. 1161/jaha.116.003872

198. Asanuma H, Sanada S, Yoshitomi T, et al. Novel Synthesized Radical-Containing Nanoparticles Limit Infarct Size Following Ischemia and Reperfusion in Canine Hearts. Cardiovascular Drugs and Therapy. 2017;31(5-6):501-510. doi:10.1007/s105 57-017-6758-6 
199. Swyer TW, Strom J, Larson DF. Nanoparticle oxygen delivery to the ischemic heart. Perfusion. 2014;29(6):539-543. doi:10.1177/ 0267659114534290

200. Yu J, Li W, Yu D. Atrial natriuretic peptide modified oleate adenosine prodrug lipid nanocarriers for the treatment of myocardial infarction: in vitro and in vivo evaluation. Drug Des Devel Ther. 2018;12:1697-1706. doi:10.2147/dddt. s166749

201. Lee YS, Choi JW, Oh JE, Yun CO, Kim SW. Human relaxin gene expression delivered by bioreducible dendrimer polymer for post-infarct cardiac remodeling in rats. Biomaterials. 2016;97:164-175. doi:10.1016/j.biomaterials.2016.04.025

202. Krohn-Grimberghe M, Mitchell MJ. Nanoparticle-encapsulated siRNAs for gene silencing in the haematopoietic stem-cell niche. Nat Biomed Eng. 2020;4(11):1076-1089. doi:10.1038/ s41551-020-00623-7

203. Zhou LS, Zhao GL, Liu Q, Jiang SC, Wang Y, Zhang DM. Silencing collapsin response mediator protein-2 reprograms macrophage phenotype and improves infarct healing in experimental myocardial infarction model. J Inflammation. 2015;12:11. doi:10.1186/s12950-015-0053-8

204. Courties G, Heidt T, Sebas M, et al. In vivo silencing of the transcription factor IRF5 reprograms the macrophage phenotype and improves infarct healing. J Am Coll Cardiol. 2014;63 (15):1556-1566. doi:10.1016/j.jacc.2013.11.023

205. Zhu K, Lai H, Guo C, et al. Nanovector-based prolyl hydroxylase domain 2 silencing system enhances the efficiency of stem cell transplantation for infarcted myocardium repair. Int J Nanomedicine. 2014;9:5203-5215. doi:10.2147/ijn.s71586

206. Hao T, Li J, Yao F, et al. Injectable Fullerenol/Alginate Hydrogel for Suppression of Oxidative Stress Damage in Brown Adipose-Derived Stem Cells and Cardiac Repair. ACS Nano. 2017;11(6):5474-5488. doi:10.1021/acsnano.7b00221

207. Yin Q, Pei Z, Wang H, Zhao Y. Cyclosporine A-nanoparticles enhance the therapeutic benefit of adipose tissue-derived stem cell transplantation in a swine myocardial infarction model. Int J Nanomedicine. 2014;9:17-26. doi:10.2147/ijn.S52005

208. Ma Q, Yang J, Huang X, et al. Poly(Lactide-Co-Glycolide)Monomethoxy-Poly-(Polyethylene Glycol) Nanoparticles Loaded with Melatonin Protect Adipose-Derived Stem Cells Transplanted in Infarcted Heart Tissue. Stem Cells. 2018;36 (4):540-550. doi:10.1002/stem.2777

209. Ishii M, Shibata R, Shimizu Y, et al. Multilayered adipose-derived regenerative cell sheets created by a novel magnetite tissue engineering method for myocardial infarction. Int J Cardiol. 2014;175 (3):545-553. doi:10.1016/j.ijcard.2014.06.034

210. Mao Y, Hu Y, Feng W, et al. Effects and mechanisms of PSS-loaded nanoparticles on coronary microcirculation dysfunction in streptozotocin-induced diabetic cardiomyopathy rats. Biomed Pharmacother. 2020;121:109280. doi:10.1016/j.biopha. 2019.109280
211. Czyzynska-Cichon I, Janik-Hazuka M, Szafraniec-Szczęsny J, et al. Low Dose Curcumin Administered in Hyaluronic Acid-Based Nanocapsules Induces Hypotensive Effect in Hypertensive Rats. Int J Nanomedicine. 2021;16:1377-1390. doi:10.2147/ijn.S291945

212. Tadin-Strapps M, Robinson M, Le Voci L, et al. Development of lipoprotein(a) siRNAs for mechanism of action studies in non-human primate models of atherosclerosis. $J$ Cardiovasc Transl Res. 2015;8(1):44-53. doi:10.1007/s12265-014-9605-1

213. Dudhipala N, Veerabrahma K. Candesartan cilexetil loaded solid lipid nanoparticles for oral delivery: characterization, pharmacokinetic and pharmacodynamic evaluation. Drug Deliv. 2016;23 (2):395-404. doi:10.3109/10717544.2014.914986

214. Chen Y, Zeng Y, Zhu X, et al. Significant difference between sirolimus and paclitaxel nanoparticles in anti-proliferation effect in normoxia and hypoxia: the basis of better selection of atherosclerosis treatment. Bioactive Materials. 2021;6(3):880-889. doi:10.1016/j.bioactmat.2020.09.005

215. Akhlaghi S, Rabbani S, Alavi S, et al. Green formulation of curcumin loaded lipid-based nanoparticles as a novel carrier for inhibition of post-angioplasty restenosis. Mater Sci Eng C Mater Biol Appl. 2019;105:110037. doi:10.1016/j.msec.2019.110037

216. Di Francesco V, Gurgone D, Palomba R, et al. Modulating Lipoprotein Transcellular Transport and Atherosclerotic Plaque Formation in ApoE(-/-) Mice via Nanoformulated Lipid-Methotrexate Conjugates. ACS Appl Mater Interfaces. 2020;12(34):37943-37956. doi:10.1021/acsami.0c12202

217. Mishra S, Bedja D, Amuzie C, et al. Improved intervention of atherosclerosis and cardiac hypertrophy through biodegradable polymer-encapsulated delivery of glycosphingolipid inhibitor. Biomaterials. 2015;64:125-135. doi:10.1016/j.biomaterials.20 15.06.001

218. Barbieri LR, Lourenço-Filho DD, Tavares ER, et al. Influence of Drugs Carried in Lipid Nanoparticles in Coronary Disease of Rabbit Transplanted Heart. Ann Thorac Surg. 2017;104 (2):577-583. doi:10.1016/j.athoracsur.2016.12.044

219. Gomes FLT, Maranhão RC, Tavares ER, et al. Regression of Atherosclerotic Plaques of Cholesterol-Fed Rabbits by Combined Chemotherapy With Paclitaxel and Methotrexate Carried in Lipid Core Nanoparticles. J Cardiovasc Pharmacol Ther. 2018;23(6):561-569. doi:10.1177/1074248418778836

220. Daminelli EN, Martinelli AE, Bulgarelli A, Freitas FR, Maranhão RC. Reduction of Atherosclerotic Lesions by the Chemotherapeutic Agent Carmustine Associated to Lipid Nanoparticles. Cardiovascular Drugs and Therapy. 2016;30 (5):433-443. doi:10.1007/s10557-016-6675-0

221. Huang Y, Yu L, Ren J, et al. An activated-platelet-sensitive nanocarrier enables targeted delivery of tissue plasminogen activator for effective thrombolytic therapy. $J$ Controlled Release. 2019;300:1-12. doi:10.1016/j.jconrel.2019.02.033
International Journal of Nanomedicine

\section{Publish your work in this journal}

The International Journal of Nanomedicine is an international, peerreviewed journal focusing on the application of nanotechnology in diagnostics, therapeutics, and drug delivery systems throughout the biomedical field. This journal is indexed on PubMed Central, MedLine, CAS, SciSearch ${ }^{\mathbb{R}}$, Current Contents ${ }^{\mathbb{B}} /$ Clinical Medicine,
Journal Citation Reports/Science Edition, EMBase, Scopus and the Elsevier Bibliographic databases. The manuscript management system is completely online and includes a very quick and fair peer-review system, which is all easy to use. Visit http://www.dovepress.com/ testimonials.php to read real quotes from published authors. 